\title{
MIGRAÇÕES INTERNACIONAIS E ESPAÇOS TRANSFRONTEIRIÇOS NO BRASIL: UMA APLICAÇÃO DE MEDIDAS DE AUTOCORRELAÇÃO ESPACIAL
}

\author{
International migration and cross-border areas in Brazil: \\ an application of spatial autocorrelation measures
}

Migraciones Internacionales y espacios transfronterizosenel Brasil: Una aplicación de medidas de autocorrelación espacial

\section{Fernando Gomes Braga}

Doutorado em Demografia pelo Centro de Desenvolvimento e Planejamento Regional da Universidade Federal de Minas Gerais. Professor de Geografia do Instituto Federal de Minas Gerais

E.mail:f.braga@ifmg.edu.br

\section{Dimitri Fazito de Almeida Rezende}

Doutorado em Demografia pela Universidade Federal de Minas Gerais (2005). Professor do Departamento de Sociologia da UFMG.email: dfazito@gmail.com

\section{Everton Emanuel Campos de Lima}

Doutorado em Demografia pelo Centro de Planejamento e Desenvolvimento Regional CEDEPLAR/ UFMG (2010). Professor do Instituto de Filosofia e Ciências Humanas e Pesquisador do Núcleo de Estudos de População - Elza Berquó, Universidade Estadual de Campinas (Unicamp) - Campinas (SP), Brasil E.mail: everton.emanuel@gmail.com

\section{Resumo}

A segunda metade do século XX ficou marcada por um aumento e diversificação dos fluxos migratórios internacionais, como resultado das oportunidades de mobilidade social abertas para algumas comunidades nos países em desenvolvimento. $\mathrm{O}$ aumento das trocas populacionais entre países da América Latina registrado nas últimas décadas colocou o Brasil na posição de polo de atração regional, especialmente para os países de fronteira (em especial na última década). O objetivo deste trabalho é contribuir para a interpretação deste novo papel ocupado pelo Brasil na rede migratória da América do Sul, a partir da aplicação de indicadores de autocorrelação espacial às taxas de migração das microrregiões geográficas. Os centros identificados pelo modelo aparentemente sustentam um agrupamento espacial de comunidades que podem ser entendidas como "comunidades transfronteiriças", cuja identificação permite refletir a respeito do alcance espacial da migração internacional no Brasil. A análise empreendida aqui também lança luz sobre o processo de difusão das comunidades transfronteiriças, a partir do acompanhamento da evolução dos aglomerados espaciais dos fluxos de migrações internacionais de 1980 a 2000.

Palavras-chave: Migrações Internacionais; Espaços Transfronteiriços; Autocorrelação espacial. 


\begin{abstract}
The second half of the 20th century is marked by the increase and diversification of international migration flows, mainly due to the rise of social mobility opportunities of some communities in developing countries. The recent increasing of population exchange between Latin American countries has made Brazil an attractive place for international migration in the region, especially for cross-border countries in the last decade. Therefore, this work aims to study the new role played by Brazil in the migratory network of South America, by measuring the spatial autocorrelation present in the migration rates of Brazilian micro-regions. The spatial centers identified by the model pointed out the existence of spatial clusters that can be understood as "cross-border communities". These last allows us to reflect about the spatial extent of international migration in Brazil. This analysis also highlights the diffusion process of cross-border communities, by analyzing the spatial development of international migration clusters from 1980 until 2000.
\end{abstract}

Key-words:International Migration; Cross-border Spaces; Spatial Autocorrelation.

\title{
Resumen
}

La segunda mitaddelsiglo XX estuvo marcada por un aumento y diversificación de losflujosmigratoriosinternacionales, como resultado de las oportunidades de movilidad social abiertas para algunas comunidades enlos países endesarrollo. El aumento del intercambio poblacional entre los países de América Latina, registrado enlas últimas décadas, coloco al Brasil en una posición de polo de atracción regional, especialmente para aquellos países conlos que tienefronteracomún (en especial durante la última década). Este trabajotiene como objetivo contribuir enlainterpretacióndelnuevo papel ocupado por el Brasil enlaredmigratoriaen América delSur, a partir del uso de indicadores de autocorrelación espacial a lastasas de migración de lasmicrorregiones geográficas. Los centros identificados por el modelo aparentemente sustentanunagrupamiento espacial de comunidades que pueden ser entendidas como "comunidades transfronterizas" y suidentificación permite reflexionar sobre el alcance de lamigración internacional enel Brasil. El análisis realizado, tambiéntrae a la luz elproceso de difusión de las comunidades transfronterizas a partir de laevolución de los conglomerados espaciales de losflujos de migracióninternacionales de 1980 a 2000.

Palabras-clave:Migraciones, Espaciostransfronterizos; autocorrelación espacial. 


\section{INTRODUÇÃO}

Este artigo tem como objetivo investigar os padrões de dispersão espacial das comunidades de migrantes do cone-sul que fixaram residência no Brasil entre 1980 e 2000. A partir da análise dos padrões de localização dos migrantes oriundos da Argentina, Paraguai, Uruguai e Bolívia mapeou-se os polos regionais nos quais se constituíram comunidades associadas à migração fronteiriça. Trata-se de um conjunto de movimentos migratórios internacionais que representam um trasbordamento dos vínculos comunitários, entre migrantes e não migrantes, para além dos limites desses Estados Nacionais. Tal conformação social materializa a própria fronteira, tendo em conta que esta representa um campo de forças sociais que se coloca na transição entre dois países, bem como constrói uma territorialidade particular no interior de cada nação. Neste sentido, explora-se aqui a oposição e a complementaridade dos conceitos de território e fronteira (Machado, 1998; Hissa, 2002; Haesbaert, 2004).

Estimativas realizadas para o saldo migratório internacional brasileiro dão conta de que as trocas do país com outras nações têm representado perda de população, a partir da década de 1980 (Carvalho e Garcia 2002). Tal evento configura uma situação inédita para o Brasil, cuja consolidação econômica e cultural se deu através da interação entre grupos de migrantes europeus, africanos e ameríndios, sempre com saldos migratórios positivos. Não obstante, no caso das relações do Brasil com o restante da América do Sul, continente em que ocupa posição de polo regional, os Censos de 1991 e 2000 mostraram incremento positivo desses imigrantes, à exceção do Chile. A inserção do Brasil nos circuitos de migração internacional, assim, tem se dado em duas diferentes dimensões: i) como emissor de migrantes para as nações desenvolvidas, notadamente EUA, Japão e Europa Ocidental; ii) Como polo regional de atração para as nações na fronteira sul-americana. Este trabalho dedicará atenção à forma como esse segundo papel desempenhado pelo Brasil tem contribuído para a conformação do seu território.

Tendo em conta o caráter seletivo da migração e, em especial, da migração internacional, é importante considerar que esses movimentos restringem-se aos indivíduos capazes de acessar determinadas redes sociais de favorecimento à viagem e/ou inserção nas sociedades de destino. Tais redes, podendo ser institucionalizadas ou não, permitem a redução dos riscos inerentes ao projeto migratório, possibilitando o estabelecimento de vínculos entre origem e destino, que irão gerar um efeito multiplicador dos movimentos e da associatividade entre os migrantes e não-migrantes (Massey et al., 1993; Guilmoto e Sandron, 2001). Tal efeito é ainda mais perceptível nas migrações de fronteira, cuja es- 
pacialidade peculiar amplia a possibilidade de criação de redes transfronteiriças eficientes para mobilizar recursos e pessoas entre os territórios. Considerando que as comunidades onde a migração se estabelece engendram os mecanismos de perpetuação dos movimentos (Sayad,1998), já que reúnem os atores sociais que intermedeiam os fluxos (migrantes retornados, familiares, amigos, agenciadores, etc.), torna-se indispensável descrever os mecanismos que atuam na determinação da distribuição espacial dessas comunidades ao longo do tempo.

Boa parte da literatura recente, produzida sobre as migrações internas e internacionais no Brasil contemporâneo, traz indicações teóricas e empíricas sobre fortes mudanças no padrão dos movimentos a partir da década de 1980 (Pacheco e Patarra, 1997; Patarra e Baeninger, 2004). No caso específico das relações do Brasil com o cone-sul, interpreta-se que as crises econômicas das décadas de 1970 e 1980 foram importantes para mobilizar determinadas comunidades em direção ao Brasil, consolidando o país como polo regional de atração (Sala, 2005; Lobo et al., 2005). Este trabalho buscará avançar nesse esforço, demonstrando os impactos territoriais desses novos padrões a partir da aplicação de técnicas de estatística espacial. Procurou-se delimitar os espaços regionais cuja presença da migração internacional se destaca em relação ao restante do país. Com a aplicação da metodologia aqui proposta, identificou-se a estrutura espacial das redes de migração internacional sustentadas pelos imigrantes internacionais (brasileiros retornados e estrangeiros), distinguindo-se quatro fluxos de imigração: Argentina, Bolívia, Paraguai e Uruguai. Entre os resultados mais importantes do estudo merece destaque a possibilidade de verificar a difusão da migração internacional pelo território, evidente na comparação realizada entre os censos brasileiros dos anos de 1991 e 2000.

\section{Migração internacional, redes e comunidades transfronteiriças}

O estudo da migração internacional é, sem dúvida, um dos mais importantes temas do debate recente sobre reestruturação geopolítica, socioeconômica e cultural do espaço mundial desencadeada pela recente fase da globalização. Neste contexto, nota-se que a mobilidade geográfica tem ganhado força, dado que as conexões entre os lugares ampliam o acesso à informação e facilitam a estruturação de redes transfronteiriças de migrantes (Vertovec, 2001; Faist, 2001; Smith e Guarnizo, 1998; Pries, 1999; Foner, 1997). Mesmo que ainda não tenha alcançado proporções similares às migrações internacionais do final do século XIX, o padrão migratório que se estrutura na segunda metade do século XX ultrapassa o anterior em conteúdo e significado: não somente as opções de origem e destino multiplicam-se em todo o planeta, como também as categorias de fluxos, as mo- 
tivações para os movimentos, os atores sociais envolvidos, entre outros elementos (Kritz e Zlotnik, 1992; Jordan e Düvell, 2003; Castles e Miller, 2003).

A nova ordem econômica global, estabelecida a partir da década de 1970 e caracterizada por um mercado de trabalho mais flexível, impulsiona uma massa de trabalhadores a se deslocarem segundo a demanda internacional de mão de obra. Nos países receptores de migrantes, na maioria nações desenvolvidas, as baixas taxas de fecundidade que ameaçam a reposição do mercado de trabalho geram conflito entre a necessidade de estabelecer uma política migratória e as forças contrárias à aculturação, que temem a perda da identidade nacional (Massey et al., 1993; Jennissen, 2004). No outro extremo da cadeia migratória, as comunidades dos migrantes nos países de origem têm logrado os benefícios das remessas dos seus emigrados. Nesse contexto, percebe-se uma transformação radical nas sociedades de origem. A migração reestrutura o mercado interno de consumo, as possibilidades de renda dos domicílios, o mercado imobiliário, e, principalmente, a migração interfere decisivamente no estilo de vida e nas escolhas das famílias (Massey et al., 1993; Pellegrino, 2000 e 2001; Skeldon, 2008; de Haan, 2010).

As migrações internacionais no interior do cone-sul assumem um aspecto peculiar nesse sistema geral. Ao mesmo tempo em que cresce a procura da população desses países pelo mercado de trabalho na América do Norte e Europa (Novick, 2008), nota-se que a maior parte da movimentação internacional da população desses países se dá nas áreas de fronteira, especialmente em função da atração de países emergentes como Brasil e Argentina (Sales 1996; Patarra e Baeninger, 2004; Lobo et al., 2005, Sala, 2005). Essa reorganização da mão de obra entre nações em desenvolvimento revela, em conjunto com as migrações para os países desenvolvidos, o surgimento de organizações econômicas e sociais de natureza comunitária que conectam as populações envolvidas com o recente processo de internacionalização do capital. Esse modelo de "globalização popular" (Nobrega, 2009), que opera por meio das comunidades e dos laços de solidariedade, tem sido denominado por autores como Portes (1997) e Brecher et al. (2000) como a "Globalização por baixo" (Globalization from Below).

Os novos espaços sociais que emergem no contexto contemporâneo da migração internacional têm ampliado o fenômeno do transnacionalismo. ${ }^{1}$ Tais movimentos populacionais implicam em um amplo intercâmbio de recursos, discursos e práticas entre as fronteiras, conduzindo a formação e intersecção das identidades dos que transitam entre os lugares (Glick Schiller et al., 1992; Hannerz, 1996). Foi nesse contexto que emergiram,

\footnotetext{
Neste sentido, o conceito de transnacionalismo aplicado à migração não trata propriamente da existência da diversidade cultural em sociedades multiculturais, mas sim do conjunto de práticas sociais, que geralmente são determinadas pela qualidade de vida dos migrantes no país receptor (Pardo, 2008).
} 
durante a década de 1990, conceitos como "transnacionalismo", "espaços transnacionais" e "comunidades transnacionais", todos buscando expressar os novos laços sociais baseados na imigração em contexto global, que materializam no espaço físico e no tecido social um “campo de ação transnacional". A perspectiva transnacional, assim, entende a migração como um processo dinâmico de construção e reconstrução das redes sociais que controlam a mobilidade e as condições socioeconômicas dos indivíduos, famílias e comunidades na origem e no destino (Faist, 2001; de Haan, 2010). As “práticas transnacionais", então, são aquelas que tomam lugar entre as fronteiras nacionais e que requerem participação permanente das partes (origem e destino). As “comunidades transnacionais", por sua vez, são grupos que se relacionam a distância, gerando formas específicas na organização dos negócios, da participação política e das manifestações culturais² (Glick Schiller et al., 1992; Portes, 1997; Pardo, 2008; Guarnizo el al, 2003; Castles e Miller, 2003; Guarnizo, 2006).

Em que pese o fato destes conceitos se referirem a uma dinâmica global e mais recente de movimentação de mão de obra, parece mais adequado compreender os movimentos nas fronteiras dos países do Cone-sul sob a perspectiva do "transfronteirismo" (Palau, 1995). Mesmo que parte da dinâmica econômica e social recente reúna aspectos do transnacionalismo, é importante considerar que tais movimentos são observados desde o período colonial e compreendem um quadro de relações que vai além das novas formas de conexão engendradas pela fase recente da globalização. Os espaços transfronteiriços, assim, reúnem as territorialidades nas quais os fluxos populacionais, trocas econômicas, interações e mediações culturais se dão no contato entre dois ou mais países, criando uma forma social peculiar, marcada pela interação entre culturas.

\section{Migrações na fronteira: 0 Brasil como polo de atração regional}

Durante quase todo o século XX, o Brasil desempenhou papel de pequeno destaque nas trocas migratórias entre os países da América do Sul, reflexo da pequena integração regional entre o país e os outros subespaços. As condições econômicas e sociais das últimas décadas, contudo, cooperaram para uma progressiva interação entre essas nações (Patarra e Baeninger, 2006; Sala, 2005). Diante do processo de internacionalização das economias a partir da década de 1980, as sociedades latino-americanas passam a enfrentar novas conjunturas políticas e sociais que têm reverberação direta sobre a geopolítica e hierarquia dos espaços - esta geopolítica que, como contrapartida dos avanços da globalização econômica, também abre caminho para as novas demandas sociais como os direitos humanos, relações de gênero, igualdade racial, proteção às populações excluídas e meio ambiente (Yúdice, 2006).

\footnotetext{
No nível individual, ainda é possível definir o "transmigrante" como o indivíduo que participa das comunidades nas quais as
} "práticas transnacionais" permeiam grande parte do cotidiano (Glick Schiller et al., 1992; Castles e Miller, 2003). 
No triunfo das práticas neoliberais durante a década de 1980, muitos países da América do Sul conheceram uma reestruturação marcada pela crescente desregulação da economia e flexibilização das relações de trabalho. Enquanto essas políticas econômicas contribuíram para o aumento do desemprego nas periferias, a multiplicação de projetos agrícolas e a descentralização urbana, ao mesmo tempo, abriam novas possibilidades para a mobilidade da população, especialmente nas regiões de fronteira. Cabe destacar que o Mercosul (criado em 1991), que tem como meta a livre circulação de mercadorias e pessoas entre os países membros, aprofundou as relações econômicas entre Brasil, Argentina, Paraguai e Uruguai, estimulando também a mobilidade populacional segundo novas alternativas (Patarra e Baeninger, 2004 e 2006; Sala, 2005; Lobo et al., 2005; Marques, 2009).

De acordo com os dados apresentados por Sala (2005) ocorreu uma diminuição do percentual de estrangeiros na população brasileira, entre 1991 e 2000, de 0,5\% para 0,4\%. Esses números demonstram que a imigração internacional ainda tem pequena influência na composição da população brasileira. Não obstante, cresce a participação de migrantes do Cone-Sul ${ }^{3}$ entre os estrangeiros, de $13,4 \%$ para $17,3 \%$ do total. ${ }^{4} \mathrm{O}$ estreitamento das relações econômicas e sociais, observado no contexto da crescente internacionalização dessas economias, certamente multiplicará os efeitos da presença desses estrangeiros no território brasileiro, justificando estudos que lancem luz sobre o perfil e a organização desses grupos.

A Tabela 1 apresenta o total de migrantes internacionais com menos de 10 anos de residência no Brasil e que declararam algum país estrangeiro como última etapa migratória. Enquanto Sala (2005) trabalhou com todos os naturais do Cone-Sul residentes no Brasil, independemente do ano de entrada no país, o recorte populacional apresentado na Tab. 5 refere-se a todas as pessoas que fizeram movimento migratório de um país estrangeiro para o Brasil nos períodos 1981-1991 e 1990-2000. Considera-se que trabalhar com os migrantes do decênio seja mais interessante para mensurar as modificações no contingente de migrantes internacionais, bem como verificar a participação dos brasileiros na migração internacional.

Ao contrário dos dados sobre nacionalidade (apresentados por Sala, 2005), o número de migrantes internacionais no Brasil apresentou um incremento de 128,03\% (de 121.871 pessoas em 1991 para 277.905 em 2000). Essa diferença aponta para duas conclusões importantes: i) a diminuição absoluta do número de estrangeiros vivendo no país é um indicativo da característica emigratória que o Brasil vem assumindo desde meados da dé-

3 Segundo esta definição, o Cone-Sul é representado pela Argentina, Uruguai, Paraguai, Bolívia e Chile.

4 De acordo com Sala (2005) havia 767.780 estrangeiros residindo no Brasil em 1991, dos quais 102.757 eram do Cone-Sul. Em 2000, os estrangeiros perfaziam 683.830, dos quais 118.612 eram nascidos no Cone-Sul. 
cada de 1980; ii) o aumento absoluto dos imigrantes de última etapa ${ }^{5}$ reflete o aumento da migração de retorno de brasileiros. Esse fato é particularmente importante no caso das trocas migratórias com os países de fronteira, pois reforça a hipótese da formação de comunidades experimentando um trânsito constante de seus integrantes entre esses países.

Tabela 1: País e Continente de última residência dos migrantes com menos de 10 anos de moradia no Brasil - 1991 e 2000

\begin{tabular}{|c|c|c|c|c|c|c|c|}
\hline País de origem & 1991 & $\%$ em 1 & $\%$ em 2 & 2000 & $\%$ em 1 & $\%$ em 2 & $\begin{array}{l}\text { Incr.\% } \\
91-00\end{array}$ \\
\hline Paraguai & 18.732 & 36,93 & 15,37 & 61.357 & 52,86 & 22,08 & 227,56 \\
\hline Argentina & 8.794 & 17,34 & 7,22 & 15.334 & 13,21 & 5,52 & 74,37 \\
\hline Bolívia & 7.173 & 14,14 & 5,89 & 11.113 & 9,57 & 4,00 & 54,93 \\
\hline Uruguai & 3.700 & 7,29 & 3,04 & 9.666 & 8,33 & 3,48 & 161,26 \\
\hline Peru & 2.219 & 4,37 & 1,82 & 5.151 & 4,44 & 1,85 & 132,13 \\
\hline Chile & 5.366 & 10,58 & 4,40 & 3.849 & 3,32 & 1,38 & $-28,28$ \\
\hline Colômbia & 1.232 & 2,43 & 1,01 & 3.048 & 2,63 & 1,10 & 147,47 \\
\hline Venezuela & 1.335 & 2,63 & 1,10 & 2.885 & 2,49 & 1,04 & 116,12 \\
\hline Equador & 931 & 1,83 & 0,76 & 1.362 & 1,17 & 0,49 & 46,39 \\
\hline Guiana Francesa & 499 & 0,98 & 0,41 & 1.321 & 1,14 & 0,48 & 164,82 \\
\hline Guiana & 552 & 1,09 & 0,45 & 632 & 0,54 & 0,23 & 14,68 \\
\hline Suriname & 195 & 0,39 & 0,16 & 357 & 0,31 & 0,13 & 82,69 \\
\hline América do Sul (1) & 50.726 & - & 41,62 & 116.075 & - & 41,77 & 128,83 \\
\hline Europa & 30.324 & - & 24,88 & 58.563 & - & 21,07 & 93,12 \\
\hline Ásia & 14.096 & - & 11,57 & 50.076 & - & 18,02 & 255,25 \\
\hline América do Norte & 20.586 & - & 16,89 & 41.569 & - & 14,96 & 101,93 \\
\hline País de origem & 1991 & $\%$ em 1 & $\%$ em 2 & 2000 & $\%$ em 1 & $\%$ em 2 & $\begin{array}{l}\text { Incr.\% } \\
91-00\end{array}$ \\
\hline África & 3.037 & - & 2,49 & 6.725 & - & 2,42 & 121,42 \\
\hline América Central & 2.178 & - & 1,79 & 3.403 & - & 1,22 & 56,23 \\
\hline Oceania & 923 & - & 0,76 & 1.494 & - & 0,54 & 61,92 \\
\hline Total (2) & 121.871 & - & - & 277.905 & - & - & 128,03 \\
\hline
\end{tabular}

Fonte: IBGE, Censos Demográficos de 1991 e 2000

A Tabela 1 também deixa claro que as trocas populacionais do Brasil com os vizinhos da América do Sul são bem superiores aos montantes trocados com outros países. Os imigrantes provenientes deste continente correspondem a cerca de $42 \%$ de toda a imigração em 1991 e em 2000. No caso dos outros continentes, nota-se um crescimento da partici-

Os migrantes de última etapa são todos os indivíduos que realizaram alguma mudança de residência no período intercensitário (1981-1991 para o Censo de 1991 e 1990-2000 para o Censo de 2000), e que declaram o último lugar de residência. Os migrantes internacionais de última etapa necessariamente são aqueles cujo domicilio de última residência localizava-se em outro país. 
pação da Ásia como emissor de migrantes, o que se deve ao forte aumento de imigrantes provenientes do Japão (de 2.885 em 1991 para 37.138 em 2000). Além disso, América do Norte e Europa mantêm consolidadas suas relações migratórias com o Brasil.

Ao detalhar os fluxos dos países da América do Sul nota-se que, à exceção do Chile, ocorreu incremento positivo no número de migrantes provenientes dessas nações. $\mathrm{O}$ aumento mais expressivo foi nas trocas migratórias com o Paraguai, cujo total de imigrantes teve incremento de $227,56 \%$ no período. De fato, o Paraguai é o país que mais realiza trocas de migrantes com o Brasil, respondendo, em 2000, por 22,08\% de todos os imigrantes internacionais e por 52,86\% daqueles provenientes de países da América do Sul. No ranking dos países que mais enviam migrantes, fica evidente a maior integração entre os países do Mercosul, além da Bolívia. Em função disso, as análises posteriores irão centrar atenção nos fluxos desses quatro países em particular. Não obstante a menor magnitude das outras trocas migratórias fica evidente o crescimento do interesse pelo Brasil como destino migratório por parte de quase todas as nações deste continente, especialmente o Peru, a Colômbia, a Venezuela e a Guiana Francesa (Jakob, 2010).

De acordo com Sala (2005) os imigrantes do Cone-Sul têm demonstrado preferência crescente pelos estados de fronteira e, secundariamente, por São Paulo. Há indicações, inclusive, de que a mudança do padrão residencial desses imigrantes acompanhou as tendências dos movimentos migratórios internos entre as Unidades da Federação. Lobo et al. (2005), ao trabalhar com a dimensão espacial do fenômeno, identificam os municípios brasileiros com forte presença de imigrantes sulamericanos. A maior área onde estes aparecem, que compreende toda a zona de fronteira do Centro-Oeste, é dominada pela migração do Paraguai. Migrantes provenientes do Peru dominam áreas em Rondônia e no Amazonas; os da Venezuela concentram-se em municípios de Roraima; e a migração das Guianas aparece em municípios do Pará e Maranhão. Além disso, notam-se concentrações de argentinos ao longo do litoral sudeste, bem como bolivianos no interior paulista e Rio de Janeiro.

Sales (1996) esclarece que a relação migratória mais intensa com o Paraguai reflete a ocupação da fronteira deste país por brasileiros durante as décadas de 1970 e 1980, no contexto da dispersão da população agrícola do Centro-Sul. Segundo essa autora, a ocupação do Paraguai por brasileiros foi "um fluxo que pode ser considerado quase como um desvio de rota das grandes levas de migrações internas, também de desbravamento de fronteiras" (p.92). Durante a década de 1990, então, nota-se um reforço do retorno de brasileiros, contudo, dirigindo-se às áreas de fronteira e experimentando alta mobilidade interna pelas Regiões Sul e Sudeste (Sprandel, 1992; Salim, 1995; Mello Almeida, 1996; Souchaud et al., 2007; Marques, 2009). 
Os contextos econômicos nos quais se inserem esses migrantes são extremamente variados, bem como o perfil dos estrangeiros que fixaram residência no Brasil nas últimas décadas. Sala (2005) demonstra que as coortes mais jovens de nascidos no Cone-Sul vivendo no Brasil experimentaram um aumento da heterogeneidade, reunindo migrantes qualificados e com altos salários, especialmente entre argentinos e uruguaios, bem como indivíduos em ocupações marginais, especialmente no caso dos bolivianos. Contudo, a migração recente caracteriza-se por selecionar uma quantidade maior de indivíduos qualificados e do sexo feminino. Patarra e Baeninger (2004) ressaltam o papel que os migrantes argentinos qualificados têm exercido em áreas urbanas, integrando os circuitos de "trabalhadores globais", ocupados em cargos gerenciais e cuja mobilidade se dá no contexto da abertura de um mercado globalizado. Nobrega (2009) e Freitas (2010) discutem uma face mais perversa do mercado de trabalho globalizado ao descrever a inserção profissional dos bolivianos na indústria da confecção e vestuário paulista, cujo peculiar circuito migratório remonta a convênios do Brasil com esse país, bem como as estratégias de migrantes coreanos para dominar esse mercado específico no estado paulista, conformando um sistema migratório que se repete em outras grandes cidades sulamericanas. Neste contexto, as redes migratórias criadas entre o Brasil e os países de fronteira se circunscrevem no contexto maior das migrações laborais latino-americanas, cujas redes migratórias conectam os trabalhadores desses países ao mercado dual Europeu e Norte-Americano, bem como intensificam os movimentos regionais, realocando a mão de obra de acordo com a reestruturação das sociedades diante das exigências da economia globalizada, estimulando tanto a "fuga de cérebros" como também a inserção precarizada dos trabalhadores nos mercados das áreas rurais e urbanas dos países emergentes (Pellegrino, 2000 e 2001).

De fato, nas últimas três décadas assistiu-se a uma consolidação de novas redes de mobilidade no sistema migratório e, consequentemente, à formação de territórios da migração, tanto pela integração econômica de novos espaços (cidades médias, tecnopolos, fronteiras de expansão agrícola e urbana), como também pela reestruturação funcional de outros espaços, através da desindustrialização de centros metropolitanos, re-hierarquização da rede urbana, aumento da rotatividade e circularidade na migração, intensificação da pendularidade, etc. (Braga e Fazito, 2010; Lima e Braga, 2010). Em associação a esses movimentos, percebe-se também uma intensificação da mobilidade populacional nas áreas de fronteira, formando espaços nos quais a difusão do comportamento migratório conecta migrações internas e a migração internacional, abrindo caminho para a formação de novas "territorialidades" e identidades (Patarra e Baeninger, 2006; Souchaud et al., 2007; Marques, 2009). 
A proposta de identificação das porções do território brasileiro que se destacam pela alta concentração de imigrantes internacionais soma-se aos esforços de construir uma abordagem espacializada da migração. Os resultados aqui apresentados apontam para a existência de aglomerados espaciais concentradores dos migrantes provenientes da Argentina, Bolívia, Paraguai e Uruguai. Os métodos de estatística espacial aplicados possibilitaram uma visão mais precisa desses aglomerados, considerando não apenas a taxa bruta de incidência da migração, mas também a representatividade dos riscos relativos em função da distribuição dos migrantes na vizinhança das localidades.

A partir da aplicação desses recursos, pode-se aprofundar a discussão sobre a formação de territorialidades da migração internacional no Brasil. Identificar tais espaços é um primeiro passo para responder perguntas-chave para o estudo das mudanças recentes no padrão migratório brasileiro: i) em quais contextos socioeconômicos e locacionais se construíram as redes sociais de apoio à migração internacional no Brasil? ii) essas tendências migratórias têm sido capazes de se difundir pelo território? Nas seções seguintes, serão apresentados os métodos de autocorrelação espacial e a aplicação destes para identificação das territorialidades concentradoras migrantes internacionais (estrangeiros e brasileiros retornados), aprofundando as evidências empíricas desta discussão.

\section{Dados e Métodos}

As informações sobre os migrantes internacionais nos decênios 1981-1991 e 19902000 foram obtidas através dos microdados da amostra dos Censos Demográficos do Instituto Brasileiro de Geografia e Estatística (IBGE). As pesquisas censitárias identificam os migrantes a partir de três critérios básicos, quais sejam: i) a definição de um período de análise; ii) a ocorrência de uma mudança definitiva de residência; iii) a definição das unidades espaciais nas quais ocorre a mudança de residência (Carvalho e Machado, 1992). Assim, foram selecionados os indivíduos com 10 anos ou menos de residência no município em que foram entrevistados e cuja declaração de residência anterior era algum dos países estrangeiros selecionados para a análise.

É importante mencionar que os dados da amostra dos Censos Demográficos são limitados para analisar a migração internacional. Em primeiro lugar esses migrantes são uma população rara em várias localidades, sendo mais adequado o uso de surveys específicos. Em segundo lugar há possibilidade de omissão da nacionalidade caso algum migrante se encontre em situação ilegal, o que aponta um certo viés no banco de dados do IBGE, com provável omissão de migrantes internacionais em situação irregular. Contudo, a grande carência de pesquisas específicas que dimensionem essa população, mesmo nas áreas de 
fronteira, tornam os Censos Demográficos uma fonte ainda viável, especialmente em pesquisas sobre todo o território nacional, como é o caso deste trabalho.

As unidades espaciais de agregação das informações foram as microrregiões brasileiras. ${ }^{6}$ Entre as vantagens associadas à utilização deste recorte territorial citam-se: $i$ ) ao longo do período 1991-2000 as microrregiões não apresentaram desagregações geográficas, possibilitando a comparação dos resultados no espaço; $i$ ) o recorte microrregional reflete parte da organização econômica e da hierarquia urbana, tendo em conta que seus limites foram definidos com base na organização econômica e nas relações sociais no nível comunitário (IBGE, 1990), tornando esse recorte bem ajustado à abordagem aqui proposta; iii) em função da migração internacional ser um evento raro, a escolha do recorte microrregional, em detrimento dos municípios, justifica-se pela redução de possíveis resíduos nas taxas de migração, ocasionadas pelo pequeno número de eventos por unidade espacial.

As informações sobre migração internacional aqui analisadas foram discriminadas em quatro diferentes origens, a saber: Argentina, Bolívia, Paraguai e Uruguai. A escolha deste conjunto de países de origem foi realizada com base na análise dos volumes de migrantes recebidos pelo Brasil (Tabela 2). O pressuposto que orienta essa investigação, portanto, é de que as redes sociais construídas pelos vínculos entre o Brasil e esses países articularam diferentes comunidades e territórios, estabelecendo padrões diversos. Vale ainda ressaltar que as articulações entre origem e destino ocorrem entre brasileiros que tiveram uma experiência migratória internacional e retornaram ao seu país, bem como os imigrantes estrangeiros que fixaram residência no Brasil (sejam eles imigrantes internacionais sem vínculos com brasileiros, ou ainda imigrantes resultantes de efeitos indiretos do retorno de brasileiros, isto é, filhos ou cônjuges do retornado brasileiro).

Assim, para efeito da precisão na análise, os migrantes foram subdivididos entre estrangeiros e brasileiros retornados. Lobo et al. (2005) afirmam que a migração de estrangeiros e o retorno de brasileiros configuram dois eventos com implicações espaciais distintas, com o primeiro tendendo a ser mais concentrado nas áreas de fronteira, o que justifica analisar tais grupos separadamente. Não obstante, é importante considerar que, em muitos casos, há uma associação direta entre a entrada de brasileiros e estrangeiros, seja porque a entrada de estrangeiros pode ser um efeito direto ou indireto do retorno de brasileiros (indivíduos que migram em conjunto, como cônjuges e filhos), seja porque as re-

\footnotetext{
${ }_{6}^{19}$ Em1991 o Brasil possuía 4492, valor que sobe para 557 em 2007. Desde o Censo de 1991, contudo, é possível agregá-los em 558 microrregiões geográficas com a mesma área territorial. Para este estudo, contudo, foram consideradas apenas 557 microrregiões, excluindo-se a microrregião de Fernando de Noronha, pertencente ao Estado de Pernambuco. Não foi possível trabalhar com essa unidade espacial em função das condições de aplicação do modelo de estatística espacial utilizado, que exige que as unidades sejam contíguas no espaço. Como Fernando de Noronha é uma ilha, não é possível utilizá-la no modelo.
} 
des sociais de apoio ao movimento tendem a integrar indivíduos em um número reduzido de comunidades. A partir de estimativas calculadas para os Censos de 1991 e 2000, Garcia e Soares (2006) mostram que 14,1\% dos imigrantes internacionais em 1991 compunham o efeito indireto da migração de retorno, sendo 18,4\% em 2000. Cabe, contudo, testar se esse mesmo efeito se repete ao se detalhar as migrações por cada uma dessas origens. Caso essa hipótese se confirme, seria razoável supor que parte dos fluxos de brasileiros e estrangeiros em direção ao Brasil compreende um mesmo contexto relacional, no sentido de que indivíduos conviventes numa mesma localidade estão expostos a situações sociais semelhantes. ${ }^{7}$

\section{Aplicação do modelo geoestatístico}

De posse das informações sobre os migrantes internacionais segundo as procedências selecionadas, aplicou-se o modelo geoestatístico de identificação dos focos de concentração espacial dos migrantes internacionais. O processamento da metodologia compreendeu duas fases: i) cálculo de taxas padronizadas de migração para cada microrregião, nos dois períodos, segundo as procedências selecionadas; ii) aplicação dos modelos de autocorrelação espacial.

Os modelos espaciais de identificação da concentração do fenômeno demandam a produção de taxas que representem a intensidade com que a migração internacional afetou a população das microrregiões. A taxa aqui utilizada compreende a proporção de migrantes internacionais no total de migrantes da microrregião, denominada de taxa bruta de migração internacional. Os modelos de estatística espacial aqui aplicados têm, como pressuposto básico, que as informações possuem variância constante. Em função disso, as taxas padronizadas foram submetidas a um procedimento de suavização (smooth) para eliminar outliers que poderiam perturbar a constância ao longo da distribuição. Esse procedimento foi realizado no Software Geoda, no qual foram processados os indicadores de autocorrelação espacial (Anselin, 2003 e 2005 e Anselin et al., 2006).

Para identificar as territorialidades concentradoras de migrantes internacionais foram, então, aplicadas medidas de autocorrelação espacial às taxas brutas de migração. A autocorrelação espacial é a mensuração estatística da dependência espacial, que pressupõe que os eventos que ocorrem no espaço tendem a se localizar a pequenas distâncias. As medidas de autocorrelação tomam uma variável e verificam como ela se correlaciona em diferentes locais no espaço, comparando a variação da informação em cada área relativamente aos seus vizinhos (Câmara et al., 2003).

Maiores detalhamentos sobre essa questão serão discutidos adiante (ver Tabelas 2 e 3). 
Os testes globais de autocorrelação espacial, então, são estimados com base nas relações entre os valores observados numa determinada localidade e seus vizinhos, de acordo com uma matriz de vizinhança adotada. Neste estudo optou-se por trabalhar com duas medidas de autocorrelação espacial, a saber: o Índice Global de Moran, que estima uma medida geral sobre agrupamento espacial da informação; e os Indicadores Locais de Associação Espacial (LISA - Local Indicators of Spacial Association), que fornecem valores específicos de correlação espacial para cada área estudada.

O Índice Global de Moran é fruto de uma relação linear entre a variável de interesse no eixo $x$ e a soma espacial dos pesos relativos dos valores dos vizinhos no eixo y. Uma vez que o índice é similar a um coeficiente de correlação, com uma relação linear, podem-se aplicar técnicas de detecção de observações que fortemente influenciam a distribuição (Bivand et. al., 2008). Para efeito de interpretação, um valor significativo e positivo do Moran indica a existência de uma autocorrelação positiva, ou a presença de agrupamentos espaciais com valores altos (ou baixos) do fenômeno em estudo. Por outro lado, o sinal negativo indica uma autocorrelação negativa ou tendência de justaposição entre valores altos e baixos do evento no espaço. A hipótese nula assume que a distribuição da informação é homogênea no espaço (Zhang e Lin, 2007).

O índice global pode ainda ser reduzido em testes locais, com o intuito de detectar clusters, ou localidades com características similares aos seus vizinhos (hotspots). Uma dessas medidas é o LISA, construído através dos $n$ componentes que, juntos, formam o Índice Global de Moran. Esse indicador de autocorrelação espacial local permite, portanto, a decomposição de indicadores globais para analisar as contribuições individuais de cada observação. Segundo Anselin (1995) os indicadores locais de associação espacial atendem às seguintes condições: 1) a correlação para uma observação é o indicador de significantes agrupamentos espaciais com valores similares àquela observação; 2) a soma dos indicadores locais é proporcional ao indicador global de correlação espacial. Em termos analíticos, o indicador para uma observação $y_{i}$ na localidade $i$ é definido da seguinte forma:

$$
L_{i}=f\left(y_{i^{\prime}} y_{j i}\right)
$$

Onde $f$ é a função e $y_{j i}$ são os valores observados nas vizinhanças $J_{i}$ da localidade $i$. A estrutura de vizinhança $J_{i}$ para cada observação é definida através das médias dos pesos espaciais (ou uma matriz de vizinhança) para cada localidade $i$. Da mesma forma que o indicador global, os LISA são indicadores de agrupamentos espaciais significativos, e cuja hipótese nula assume a não existência de autocorrelação espacial local (Anselin, 1995).

Dessa maneira, as microrregiões selecionadas com forte concentração de migrantes 
internacionais são aquelas em que se identificou uma concentração significativamente alta de migrantes, em comparação com as microrregiões vizinhas. A próxima seção apresenta os resultados da aplicação desses dois indicadores para as taxas brutas de migração, de acordo com as procedências selecionadas, para a migração internacional ocorrida entre 1981-1991 e 1990-2000.

\section{Resultados}

Em primeiro lugar, procurou-se mensurar o nível de dependência existente entre a migração de retorno de brasileiros e a imigração de estrangeiros, a fim de delimitar o quanto estes dois grupos podem ser encarados como participantes de dinâmicas migratórias separadas ou correlatas. As Tabelas 2 e 3 apresentam informações que podem elucidar essa questão. A primeira apresenta a distribuição dos imigrantes de cada uma das procedências selecionadas, segundo a nacionalidade e a relação com o chefe de domicílio. Já a Tabela 3 apresenta os mesmos migrantes de acordo com a nacionalidade, discriminando os brasileiros e estrangeiros de acordo com a co-residência. Foram considerados em situação de co-residência todos os migrantes internacionais cuja declaração dos componentes do domicilio apresentou, pelo menos, um brasileiro e um estrangeiro. Os que não estavam em situação de co-residência, por sua vez, compreendem os moradores de todos os domicílios em que foram registrados apenas migrantes brasileiros ou estrangeiros.

A hipótese de movimentos inter-relacionados entre brasileiros e estrangeiros seria confirmada por uma proporção elevada de migrantes, entre os membros do domicílio, que geralmente acompanham o responsável no movimento (especialmente filhos e outros parentes). Seguindo a mesma lógica, a co-residência deveria ser elevada nesses grupos e apresentar aumento no período em estudo. Os dados aqui apresentados, contudo, parecem indicar que apenas no caso da migração Brasil-Paraguai é possível manter a hipótese de que os movimentos migratórios dos estrangeiros e de retorno de brasileiros estão diretamente relacionados.

Os migrantes oriundos da Argentina mostraram maior concentração na categoria Responsável, especialmente entre os estrangeiros. Entre 1991 e 2000, nota-se uma recomposição entre os brasileiros a favor do aumento da proporção de Filhos e diminuição de Cônjuge e outros parentes entre os brasileiros. No caso dos estrangeiros, diminui a proporção de Responsáveis, aumentando Cônjuges, Filhos e outros parentes. Não obstante, nota-se uma forte diminuição da co-residência entre os brasileiros e um pequeno aumento entre os estrangeiros, o que talvez indicasse um aumento aparente das relações entre esses grupos. Contudo, a elevação do número de migrantes parece ter reforçado dinâmicas separadas. 
No caso das migrações da Bolívia, os brasileiros se organizam de uma forma bem peculiar, com baixo percentual de Responsáveis em 1991 e forte presença de Filhos, situação que se modifica em 2000. No caso dos estrangeiros, há uma diminuição na participação dos Responsáveis e Filhos e um incremento no percentual de Cônjuges, bem como de outros parentes. Isso indica que o movimento migratório tem fortalecido redes sociais que possibilitam a participação de outros componentes da família no movimento, ainda que os dados não permitam considerações mais profundas sobre o assunto. Tal hipótese apenas se reforça ao se constatar que a co-residência tem baixa participação nesta migração.

Tabela 2: Migrantes internacionais de última etapa procedentes da Argentina, Bolívia, Paraguai e Uruguai segundo nacionalidade e relação com o responsável pelo domicílio

\begin{tabular}{|c|c|c|c|c|c|c|c|c|}
\hline \multicolumn{9}{|c|}{1991} \\
\hline \multirow{3}{*}{$\begin{array}{l}\text { Relação com o responsável } \\
\text { pelo domicílio }\end{array}$} & \multicolumn{2}{|c|}{ Argentina } & \multicolumn{2}{|c|}{ Bolívia } & \multicolumn{2}{|c|}{ Paraguai } & \multicolumn{2}{|c|}{ Uruguai } \\
\hline & \multicolumn{8}{|c|}{ Brasileiros } \\
\hline & $\begin{array}{l}\text { No. } \\
\text { abs. }\end{array}$ & $\%$ & $\begin{array}{l}\text { No. } \\
\text { abs. }\end{array}$ & $\%$ & $\begin{array}{l}\text { No. } \\
\text { abs. }\end{array}$ & $\%$ & $\begin{array}{l}\text { No. } \\
\text { abs. }\end{array}$ & $\%$ \\
\hline Pessoa responsável & 719 & 29,4 & 247 & 17,2 & 4.002 & 26,8 & 159 & 20,8 \\
\hline Cônjuge, companheiro(a) & 555 & 22,7 & 297 & 20,7 & 3.411 & 22,8 & 214 & 28,0 \\
\hline Filho(a), enteado(a) & 748 & 30,6 & 677 & 47,1 & 6.124 & 41,0 & 327 & 42,8 \\
\hline Pais/netos/irmãos/outro parente & 315 & 12,9 & 147 & 10,2 & 1.162 & 7,8 & 39 & 5,1 \\
\hline Agregado/pensionista/empregado & 52 & 2,1 & 49 & 3,4 & 195 & 1,3 & 8 & 1,0 \\
\hline Individual em domicílio coletivo & 58 & 2,4 & 20 & 1,4 & 34 & 0,2 & 18 & 2,4 \\
\hline Total & 2.446 & - & 1.438 & - & 14.929 & - & 765 & - \\
\hline \multicolumn{9}{|c|}{ Estrangeiros } \\
\hline Pessoa responsável & 2.403 & 37,9 & 1.757 & 30,6 & 610 & 16,0 & 985 & 33,6 \\
\hline Cônjuge, companheiro(a) & 1.219 & 19,2 & 1.010 & 17,6 & 744 & 19,6 & 676 & 23,0 \\
\hline Filho(a), enteado(a) & 1.906 & 30,0 & 1.418 & 24,7 & 1.648 & 43,3 & 789 & 26,9 \\
\hline Pais/netos/irmãos/outro parente & 428 & 6,7 & 838 & 14,6 & 546 & 14,4 & 328 & 11,2 \\
\hline Agregado/pensionista/empregado & 321 & 5,1 & 588 & 10,3 & 233 & 6,1 & 69 & 2,3 \\
\hline Individual em domicílio coletivo & 71 & 1,1 & 123 & 2,1 & 22 & 0,6 & 88 & 3,0 \\
\hline Total & 6.348 & - & 5.735 & - & 3.803 & - & 2.935 & - \\
\hline \multicolumn{9}{|c|}{2000} \\
\hline \multicolumn{9}{|c|}{ Brasileiros } \\
\hline Pessoa responsável & 2.051 & 29,9 & 1.225 & 26,5 & 13.343 & 26,6 & 1.016 & 24,0 \\
\hline Cônjuge, companheiro(a) & 1.386 & 20,2 & 690 & 14,9 & 10.512 & 20,9 & 878 & 20,7 \\
\hline Filho(a), enteado(a) & 2.582 & 37,7 & 1.731 & 37,4 & 21.204 & 42,2 & 1.836 & 43,4 \\
\hline Pais/netos/irmãos/outro parente & 662 & 9,7 & 750 & 16,2 & 4.450 & 8,9 & 415 & 9,8 \\
\hline Agregado/pensionista/empregado & 88 & 1,3 & 202 & 4,4 & 456 & 0,9 & 55 & 1,3 \\
\hline Individual em domicílio coletivo & 81 & 1,2 & 26 & 0,6 & 236 & 0,5 & 34 & 0,8 \\
\hline Total & 6.851 & - & 4.624 & - & 50.201 & - & 4.235 & - \\
\hline
\end{tabular}




\section{Estrangeiros}

\begin{tabular}{lllllllll} 
Pessoa responsável & 2.898 & 34,2 & 1.896 & 29,2 & 1.752 & 15,7 & 1.815 & 33,4 \\
\hline Cônjuge, companheiro(a) & 1.973 & 23,3 & 1.472 & 22,7 & 1.851 & 16,6 & 1.549 & 28,5 \\
\hline Filho(a), enteado(a) & 2.649 & 31,2 & 1.285 & 19,8 & 5.443 & 48,8 & 1.446 & 26,6 \\
\hline Pais/netos/irmãos/outro parente & 743 & 8,8 & 1.375 & 21,2 & 1.711 & 15,3 & 464 & 8,5 \\
\hline Agregado/pensionista/empregado & 108 & 1,3 & 361 & 5,6 & 336 & 3,0 & 132 & 2,4 \\
\hline Individual em domicílio coletivo & 112 & 1,3 & 99 & 1,5 & 62 & 0,6 & 25 & 0,5 \\
\hline Total & 8.483 & - & 6.489 & - & 11.156 & - & 5.431 & - \\
\hline
\end{tabular}

Fonte: IBGE, Censos Demográficos de 1991 e 2000.

No caso das relações Brasil-Paraguai nota-se um forte predomínio da categoria Filhos entre os estrangeiros, associado ao mais baixo percentual de Responsável entre as estruturas aqui comparadas. Comparando com as informações da Tabela 3, parece razoável supor que parte significativa da migração de estrangeiros do Paraguai para o Brasil associa-se ao movimento de brasileiros, compondo efeitos diretos e indiretos. Portanto, esse também é um indicativo do reforço das redes sociais e da abertura de canais de mobilização de filhos e parentes para fixarem residência no Brasil. Vale destacar que este é o único caso de aumento da co-residência entre brasileiros e estrangeiros no período, e apresenta a única situação em que os co-residentes são mais numerosos (estrangeiros em 2000). Finalmente, chama a atenção na migração proveniente do Uruguai o alto percentual de Filhos entre os brasileiros nos dois períodos e o aumento, entre 1991 e 2000, da categoria Cônjuge entre os estrangeiros. Assim como no caso da Argentina, não parece haver indicações, nos dados, de fortes relações entre esses dois grupos de migrantes. 


\begin{tabular}{|c|c|c|c|c|c|c|c|c|c|}
\hline \multirow{3}{*}{\multicolumn{2}{|c|}{$\begin{array}{l}\text { País de origem/ } \\
\text { co-residência }\end{array}$}} & \multicolumn{4}{|c|}{1991} & \multicolumn{4}{|c|}{2000} \\
\hline & & \multicolumn{2}{|c|}{ Brasileiros } & \multicolumn{2}{|c|}{ Estrangeiros } & \multicolumn{2}{|c|}{ Brasileiros } & \multicolumn{2}{|c|}{ Estrangeiros } \\
\hline & & $\begin{array}{l}\text { No. } \\
\text { abs. }\end{array}$ & $\%$ & $\begin{array}{l}\text { No. } \\
\text { abs. }\end{array}$ & $\%$ & $\begin{array}{l}\text { No. } \\
\text { abs. }\end{array}$ & $\%$ & $\begin{array}{l}\text { №. } \\
\text { abs. }\end{array}$ & $\%$ \\
\hline \multirow{3}{*}{ Argentina } & $\begin{array}{c}\text { Sem } \\
\text { co-residência }\end{array}$ & 1.609 & 65,8 & 5.285 & 83,3 & 5.559 & 81,1 & 6.819 & 80,4 \\
\hline & $\begin{array}{c}\text { Em } \\
\text { co-residência }\end{array}$ & 837 & 34,2 & 1.063 & 16,7 & 1.292 & 18,9 & 1.664 & 19,6 \\
\hline & Total & 2.446 & - & 6.348 & - & 6.851 & - & 8.483 & - \\
\hline \multirow{3}{*}{ Bolívia } & $\begin{array}{c}\text { Sem } \\
\text { co-residência }\end{array}$ & 1.103 & 76,7 & 5.342 & 93,2 & 4.074 & 88,1 & 5.958 & 91,8 \\
\hline & $\begin{array}{c}\text { Em } \\
\text { co-residência }\end{array}$ & 335 & 23,3 & 392 & 6,8 & 550 & 11,9 & 531 & 8,2 \\
\hline & Total & 1.438 & - & 5.735 & - & 4.624 & - & 6.489 & - \\
\hline \multirow{3}{*}{ Paraguai } & $\begin{array}{c}\text { Sem } \\
\text { co-residência }\end{array}$ & 12.988 & 87,0 & 2.542 & 66,8 & 43.159 & 86,0 & 5.563 & 49,9 \\
\hline & $\begin{array}{c}\text { Em } \\
\text { co-residência } \\
\end{array}$ & 1.941 & 13,0 & 1.261 & 33,2 & 7.042 & 14,0 & 5.593 & 50,1 \\
\hline & Total & 14.929 & - & 3.803 & - & 50.201 & - & 11.156 & - \\
\hline \multirow{3}{*}{ Uruguai } & $\begin{array}{c}\text { Sem } \\
\text { co-residência }\end{array}$ & 587 & 76,8 & 2.589 & 88,2 & 3.747 & 88,5 & 4.914 & 90,5 \\
\hline & $\begin{array}{c}\text { Em } \\
\text { co-residência }\end{array}$ & 177 & 23,2 & 346 & 11,8 & 488 & 11,5 & 518 & 9,5 \\
\hline & Total & 765 & - & 2.935 & - & 4.235 & - & 5.431 & - \\
\hline
\end{tabular}

Fonte: IBGE, Censos Demográficos de 1991 e 2000.

Esses dados mostram a necessidade de se considerar individualmente os impactos territoriais da migração de brasileiros e estrangeiros, já que apenas no caso do Paraguai é possível falar de alta dependência entre os grupos. Essa exploração inicial aponta a necessidade de discutir separadamente o perfil desses imigrantes, já que não parece ser possível afirmar, de forma genérica, que existe muito ou pouco efeito indireto do retorno de brasileiros, verdadeiro aqui apenas nas trocas Brasil-Paraguai. Cumpre agora verificar a distribuição espacial desses grupos.

\section{As estimativas do Índice Global de Moran e dos LISA}

A Tabela 4 traz os resultados do Índice Global de Moran para as estimativas resultantes do cálculo das taxas brutas suavizadas para os dois períodos e diferentes grupos de migração internacional. Todos os valores estimados do Índice se mostraram positivos e sig- 
nificativos. Esses indicadores revelam que na maioria dos casos, com maior ou menor intensidade, verifica-se que os migrantes internacionais tendem a se concentrar em determinados grupos de microrregiões, predominando as aglomerações (clusters) nas quais se verifica a justaposição de valores similares, ou seja, microrregiões com alto percentual de migrantes, circundadas de micros vizinhas com a mesma condição, assim como conjuntos justapostos de microrregiões com baixo percentual de migrantes.

Os valores do Moran global apontam para a conclusão de que as microrregiões vêm estabelecendo manchas, ou territorialidades, nas quais se agregam microrregiões próximas, que também vão se caracterizando pelo alto percentual de migrantes internacionais. Ao que parece, contrasta-se a esse fenômeno a existência de áreas cuja expressão dos migrantes na população total de certas microrregiões vizinhas permanece baixa, sugerindo que há incapacidade de ativar conexões que viabilizem um trânsito mais intenso de pessoas entre o Brasil e os países selecionados. De fato, considerando o papel desempenhado pelas redes sociais de estímulo à migração e tendo em conta o aumento da importância da migração internacional, nas duas últimas décadas do século XX, o indicador global contribui para confirmar a cristalização no espaço de "comunidades transfronteiriças" na vizinhança imediata de localidades que já possuíam algum tipo relação com o exterior. Tal interpretação parece se confirmar com o uso dos indicadores locais de associação espacial.

Tabela 4: Índice Global de Moran para os grupos de migrantes internacionais

\begin{tabular}{l|cc|cc|cc|cc}
\multirow{2}{*}{ País de Origem } & \multicolumn{4}{|c|}{1991} & \multicolumn{4}{c}{2000} \\
\cline { 2 - 9 } & \multicolumn{2}{|c|}{ Brasileiros } & \multicolumn{2}{|c|}{ Estrangeiros } & Brasileiros & \multicolumn{2}{c}{ Estrangeiros } \\
\hline Argentina & 0,4027 & $* * *$ & 0,0875 & $*$ & 0,4602 & $* * *$ & 0,1570 & $* *$ \\
\hline Bolívia & 0,1163 & $*$ & 0,0072 & $*$ & 0,1603 & $* *$ & 0,0072 & $*$ \\
\hline Paraguai & 0,4472 & $* * *$ & 0,1336 & $*$ & 0,5733 & $* * *$ & 0,3837 & $* * *$ \\
\hline Uruguai & 0,1121 & $*$ & 0,2418 & $* * *$ & 0,5409 & $* * *$ & 0,2595 & $* * *$ \\
\hline $\mathrm{p}<0.001^{* *}, \mathrm{p}<0.01^{* *}$ e $\mathrm{p}<0.05^{*}$ & & & & & & \\
\hline
\end{tabular}

Fonte: IBGE, Censos Demográficos de 1991 e 2000

Sabendo que a migração internacional ocorre com intensidade entre algumas comunidades dispersas pelo território, os valores do Índice Global de Moran sugerem a necessidade de uma análise fragmentada das territorialidades envolvidas com a migração, de forma a identificar em quais espaços estariam se constituindo tais comunidades, e, mais importante, se a dinâmica dos fluxos irá mostrar um padrão de localização recorrente nos dois períodos analisados, com indicações de um processo de difusão das mobilidades. 
Quando se trabalha com áreas muito grandes, como é o caso deste estudo, aumentam as chances de que diferentes regimes de associação espacial ocorram simultaneamente no espaço. A formação de múltiplas territorialidades com níveis altos e diferenciados de dependência espacial exige, assim, um exame dos padrões de forma mais detalhada. Com este objetivo específico, os valores dos LISA permitem trabalhar com um conjunto de indicadores associados a diferentes localizações espaciais. Os indicadores locais de associação espacial são, assim, índices de Moran no nível local. Desta forma, uma vez determinada a significância estatística dos LISA, são reconhecidos aglomerados de áreas ou áreas isoladas marcadas pela não-estacionariedade do evento em questão, já que tais áreas possuem uma dinâmica espacial própria (Câmara et al., 2003).

O Índice Global de Moran corresponde ao coeficiente de variação de uma reta de regressão linear, estimada a partir da comparação entre os valores normalizados dos eventos em cada área com a média dos vizinhos (Câmara et al., 2003). A plotagem desta comparação permite construir um diagrama de espalhamento das áreas em estudo (Moran Scatterplot) que, subdivido em quadrantes, permite conhecer qual a forma de associação da área com a sua vizinhança imediata. Neste sentido, há dois conjuntos básicos de associação: O primeiro refere-se à formação de clusters e ocorre quando os valores normalizados e a média dos vizinhos são, ambos, positivos ou negativos. Caso os valores sejam positivos, tem-se a formação de um cluster no qual tanto a área como os vizinhos ostentam taxas elevadas de ocorrência do evento. No caso de valores negativos, o cluster será caracterizado por taxas baixas na área e na vizinhança. A segunda possibilidade de associação refere-se à formação dos outliers. Essas áreas encontram-se nos quadrantes do Moran Scatterplot com sinais opostos entre a taxa normalizada e a média da vizinhança, ou seja, caracterizam duas situações: áreas com taxas elevadas de ocorrência do evento circundadas por outras com baixas taxas, ou então áreas com baixa ocorrência e cujos vizinhos possuem altas taxas (Anselin, 1995).

Assim, o processamento computacional dos valores de LISA permite definir quatro tipos diferentes de associação espacial para as áreas com valores significativos, que fazem referência ao padrão encontrado na área e na sua vizinhança. Entre os clusters, localidades com padrão "alto-alto" e "baixo-baixo", e entre os outliers, localidades com padrão "alto-baixo" e "baixo-alto". Os mapas temáticos apresentados a seguir representam os resultados estimados dos LISA para a imigração internacional no Brasil, nas décadas de 1980 e 1990, de acordo com as procedências selecionadas.

Os indicadores relativos à imigração da Argentina para o Brasil estão representados na Figura 1. No caso dos brasileiros, destaca-se a expansão de um cluster de padrão alto- 
-alto na área de fronteira entre esses países. Com 13 localidades em 1991, esse cluster se difunde para alcançar 29 localidades em 2000, avançando para a porção leste do Rio Grande do Sul e Santa Catarina. Em 1991, a distribuição conta com 13 localidades com associação espacial de tipo alto-baixo espalhadas na porção centro-sul do país, à exceção das microrregiões de Itapetinga(BA) e Salvador(BA), em 1991. Em 2000, aparecem outras microrregiões dessa categoria em estados no Nordeste e Norte (Cotegipe-BA, Chapadas do Alto Itapecuru-MA, Patos-PE, Angico-RN, Litoral Sul-RN, Alto Solimões-AM).

No caso dos estrangeiros em 1991, como o Índice Global já havia mostrado, ${ }^{8}$ há uma tendência à maior dispersão desses migrantes pelo território, com 16 microrregiões de tipo alto-baixo. Os clusters que começam a se formar nesse período, se consolidando em 2000, ocorrem nas mesmas localidades em que se registrou aglomeração de brasileiros. Contudo, a expressão espacial dos clusters de estrangeiros é bem menor do que no grupo anterior, individualizando uma área no sul do Rio Grande do Sul, com três microrregiões, e outra, que passa pelo extremo ocidente dos três estados do Sul, com 9 microrregiões. Merece destaque ainda a formação, em 2000, de um cluster de migrantes estrangeiros nos estados do Rio de Janeiro e São Paulo (microrregiões de São José dos Campos-SP, Caraguatatuba-SP, Guaratinguetá-SP, Baia da Ilha Grande-RJ).

Com relação às migrações da Bolívia (Figura 2), os dados de 1991 mostraram pequena tendência à formação de clusters, tanto entre brasileiros como entre estrangeiros. No primeiro caso, apenas as microrregiões de Guajará-Mirim-RO, Porto Velho-RO, Rio Branco-AC e Brasiléia-AC formam um cluster alto-alto. Além dessas, as microrregiões de Baixo Pantanal-MS e Primavera do Leste-MT, com associação alto-baixo, aparecem circundadas por localidades de tipo baixo-alto, que irão conformar, em 2000, um cluster de tipo alto-alto nos estados do Mato Grosso e Mato Grosso do Sul, em um claro processo de difusão da influência da migração por esse território.

No caso dos estrangeiros, fica evidente também que os clusters dispersos em toda a fronteira brasileira do Acre ao Mato Grosso do Sul, em 1991, conectam-se com a migração da década de 1990, formando uma extensa área de fronteira sob a influência da migração da Bolívia. Além disso, 10 microrregiões com associação de tipo baixo-alto aparecem em pontos dispersos das regiões Sul e Sudeste, indicando uma tendência dos bolivianos a difundirem sua ocupação nesses espaços, como indicado para o mercado de trabalho paulista por Nóbrega (2009) e Freitas (2010).

\footnotetext{
8 O valor do Moran Global (0,0875) foi relativamente baixo, em relação aos outros valores estimados, e apresentou baixa significância ( $p>0,05)$. Isso demonstra que o ajuste da curva global, mesmo que tenha captado tendência significativa à formação de clusters, foi menor em função de existirem padrões desviantes entre as localidades que, como demonstrado no mapa da Figura 4, relacionam-se à existência de localidades de tipo alto-baixo.
} 
Figura 1: Taxas brutas de imigração e categorias dos Índices locais de associação espacial (LISA) das microrregióes geográficas brasileiras - 1991 e 2000. Procedência: Argentina

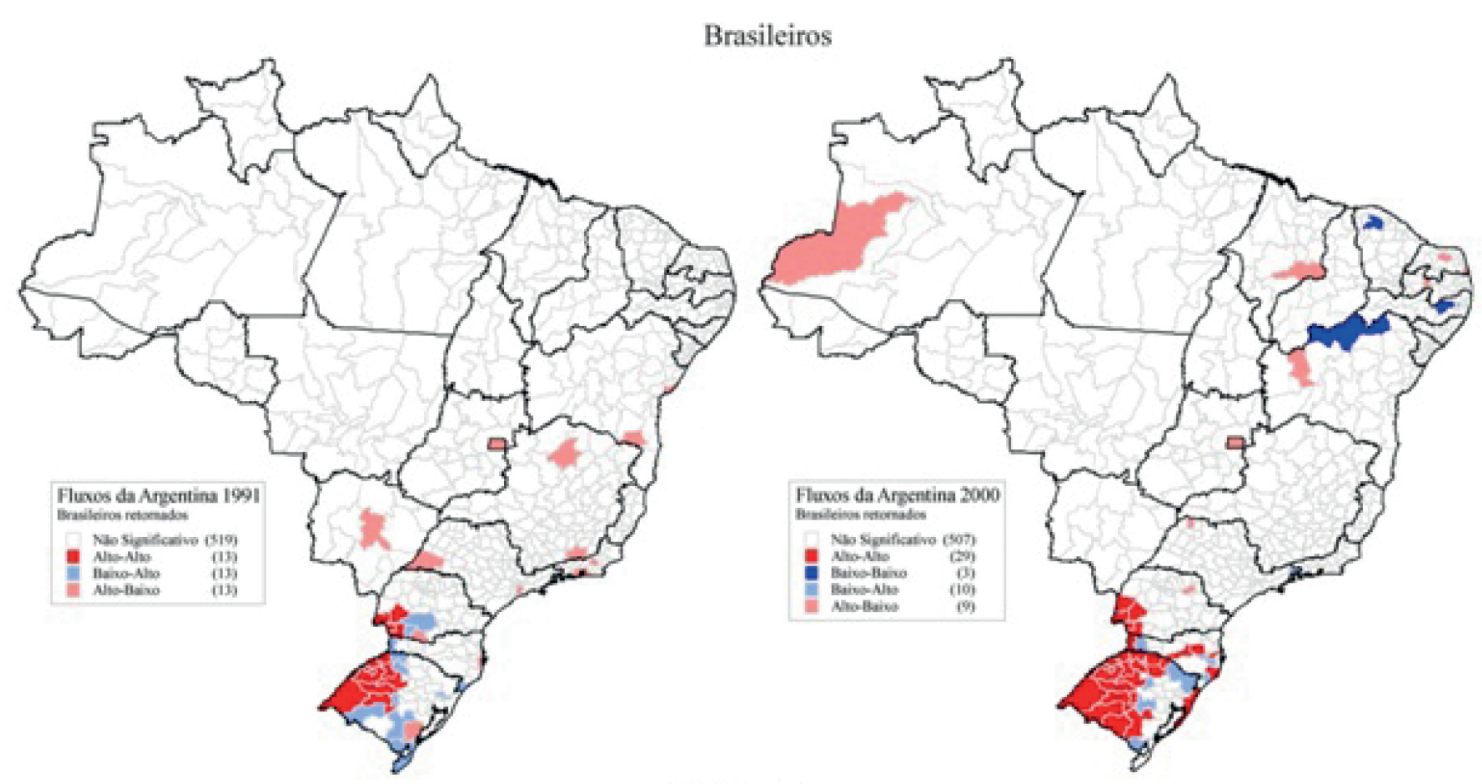

Estrangeiros

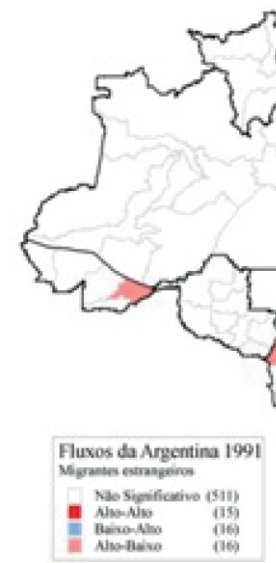

A Figura 3 deixa evidente que as trocas migratórias entre Brasil e Paraguai vêm consolidando uma porção do território nacional com forte presença desses migrantes. Tanto no caso da migração de brasileiros como entre os estrangeiros, nota-se uma expansão do cluster de tipo alto-alto por toda a fronteira Brasil-Paraguai, reunindo, em 2000, $31 \mathrm{mi}$ crorregiões para a migração de retorno e 26 para a migração de estrangeiros. Essa configuração espacial reflete um transbordamento/fusão da dinâmica migratória brasileira e paraguaia, permitindo delimitar o alcance da fronteira, bem como reconhecer a territorialidade brasileira caracterizada pela interação entre fluxos populacionais de brasileiros e paraguaios nos mesmos locais. Vale destacar que os pontos de tipo alto-baixo que apare-

a 
ciam dispersos pelo centro-sul brasileiro, em 1991, especialmente no caso dos estrangeiros, desaparecem a favor da formação deste grande cluster, o que pode indicar a formação de uma "comunidade transnacional", que integra tanto brasileiros retornados quanto imigrantes paraguaios, que também mantêm relações de proximidade com sua comunidade de origem no Paraguai. Ressalta-se ainda, no caso dos brasileiros, a identificação de clusters de tipo baixo-baixo na porção leste do território, o que evidencia que as migrações provenientes do Paraguai exercem sua influência quase que exclusivamente na franja territorial associada à fronteira com os outros países da América do Sul.

Figura 2: Taxas brutas de imigração e categorias dos Índices locais de associação espacial (LISA) das microrregiões geográficas brasileiras - 1991 e 2000. Procedência: Bolívia
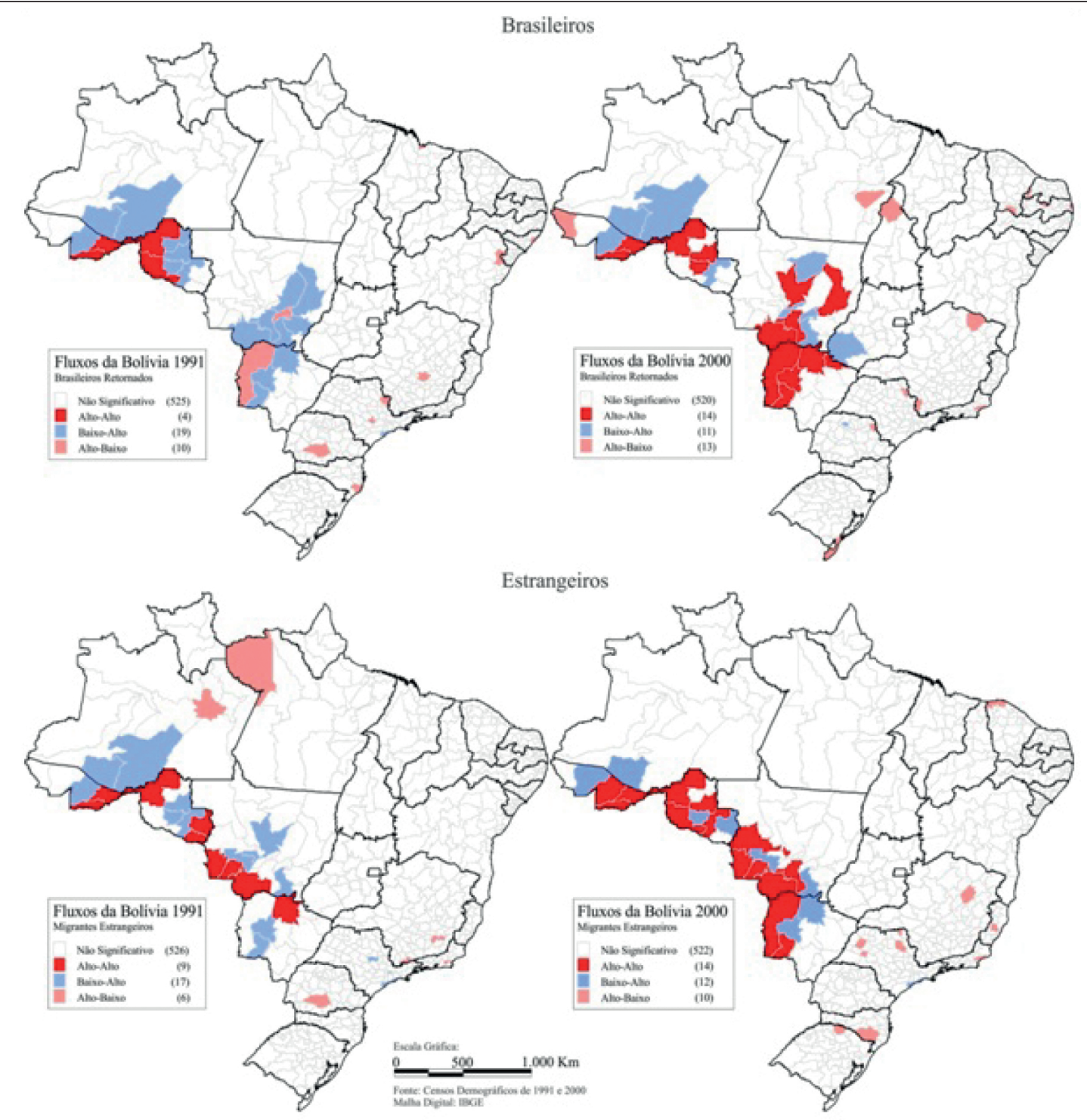
Figura 3: Taxas brutas de imigração e categorias dos Índices locais de associação espacial (LISA) das microrregiões geográficas brasileiras - 1991 e 2000. Procedência: Paraguai

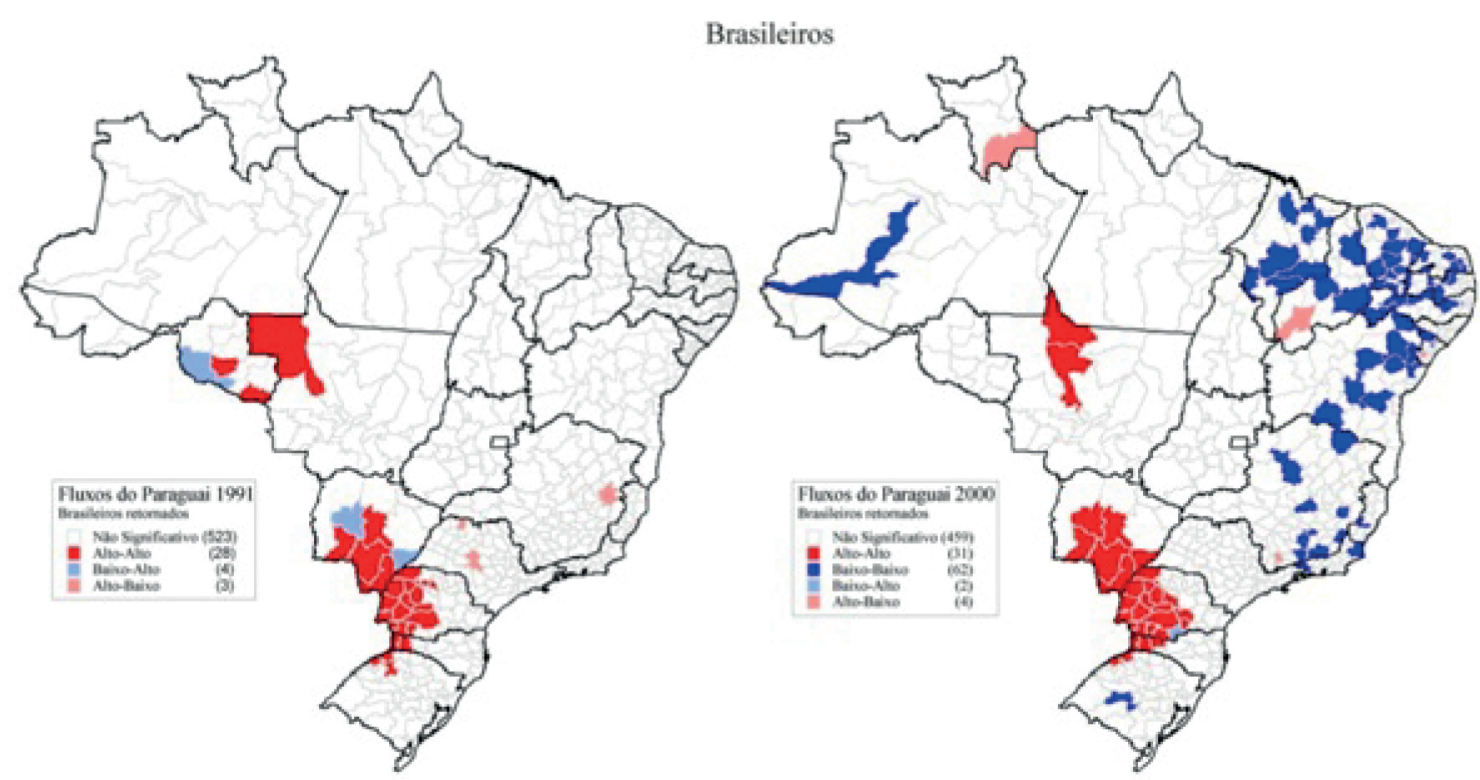

Estrangeiros

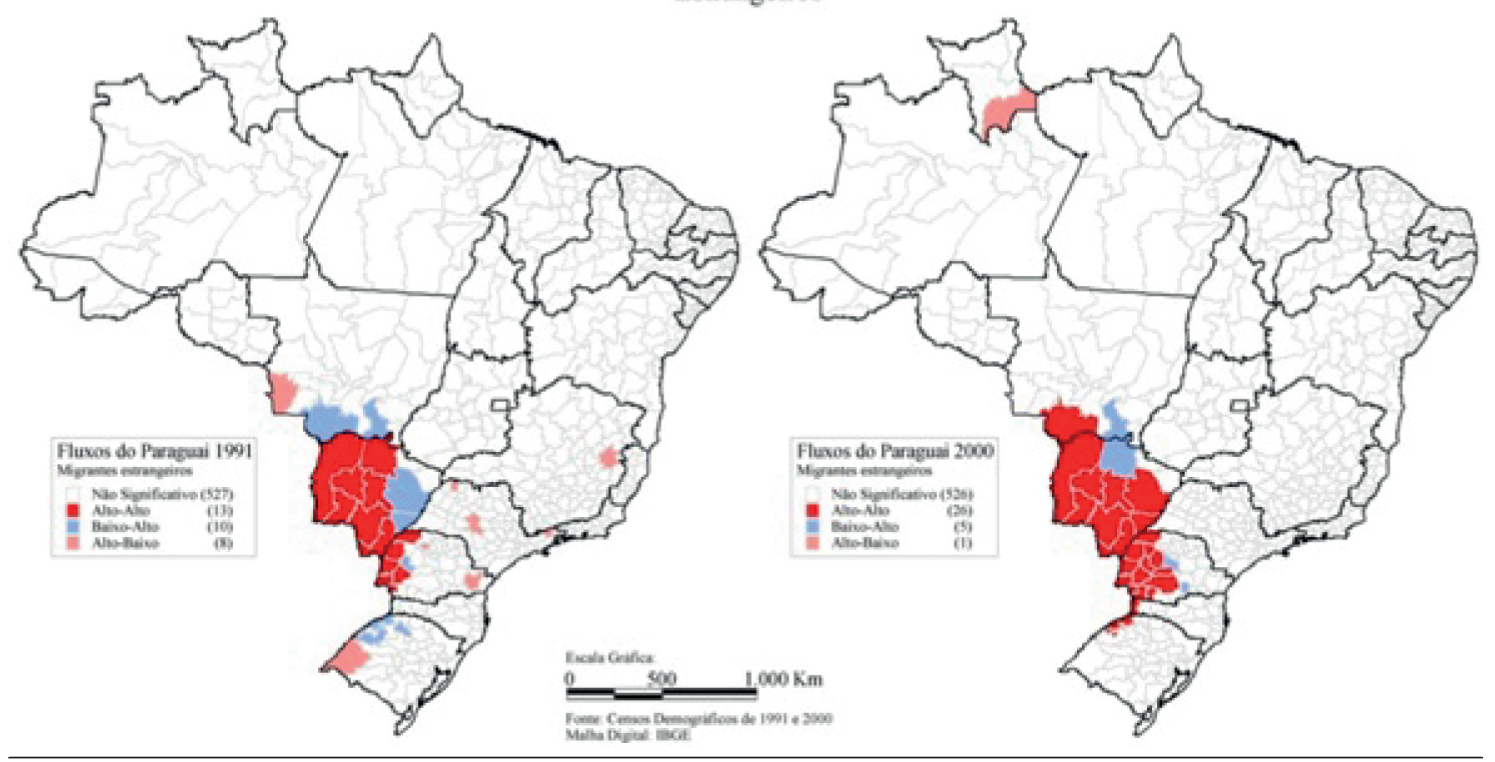

Finalmente, a Figura 4 apresenta a tipologia de associação espacial da migração proveniente do Uruguai. O padrão descrito pela migração de retorno de brasileiros deixa evidente dois padrões: $i$ ) a expansão de um cluster na fronteira Brasil-Uruguai; vale destacar que, assim como nos casos anteriores, muitas microrregiões de tipo baixo-alto em 1991 tornam-se parte do cluster alto-alto em 2000, reforçando, mais uma vez, a hipótese de um efeito difusor provocado por essas migrações ao alcançar um número maior de localidades. ii) em segundo lugar, nota-se o surgimento de mais localidades no Nordeste e no Sudeste com padrão alto-baixo. Contudo, como as análises anteriores já mostraram, esse tipo de associação tende a ser menos estável no tempo do que os clusters formados nas regiões

a 
de fronteira. No caso dos estrangeiros, o mapa demonstra a forte tendência de expansão do mesmo cluster, reforçando a presença dos Uruguaios na região fronteiriça.

\section{Figura 4: Taxas brutas de imigração e categorias dos Índices locais de associação espacial (LISA) das microrregiões geográficas brasileiras - 1991 e 2000. Procedência: Uruguai}

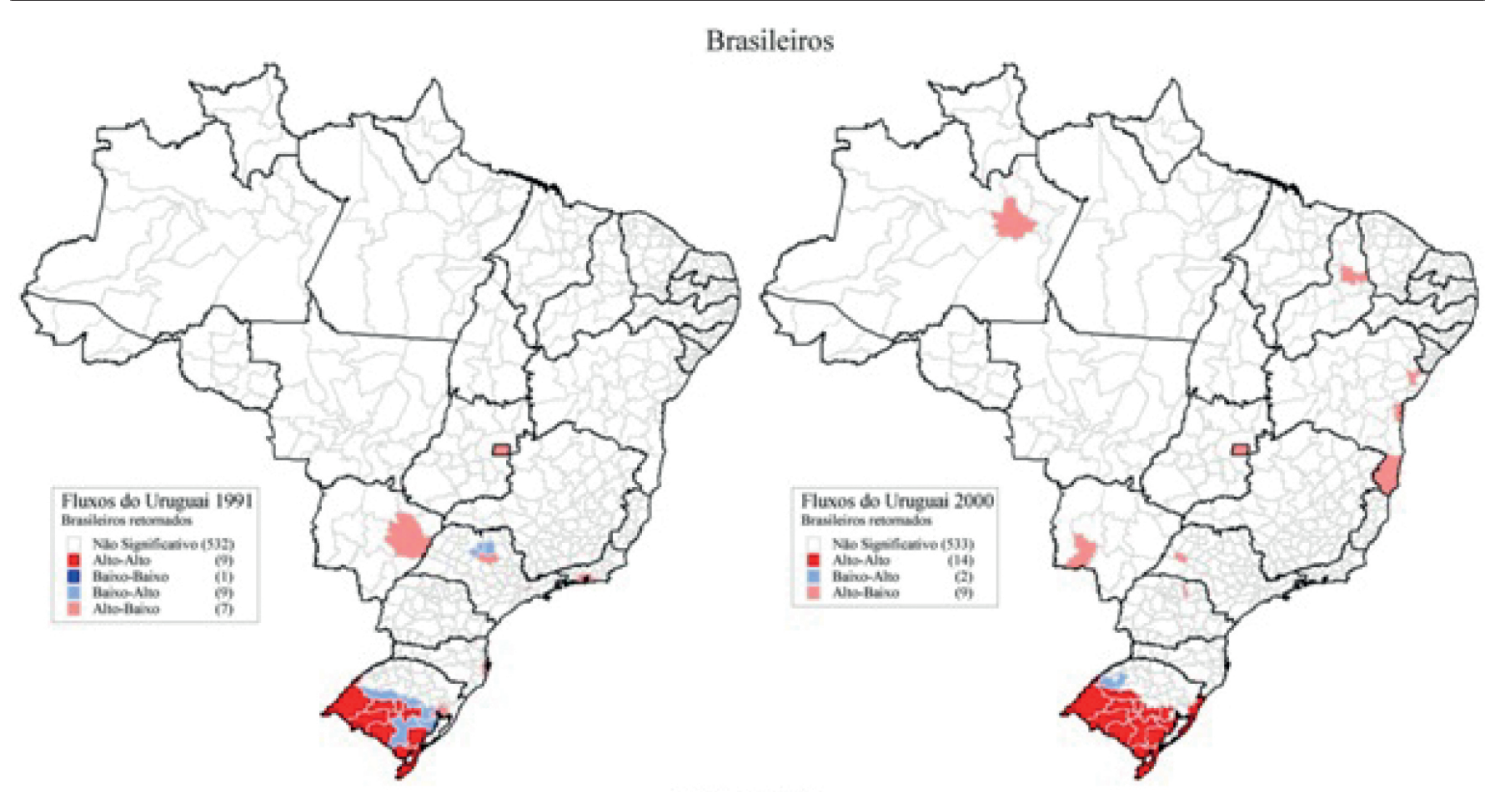

Estrangeiros

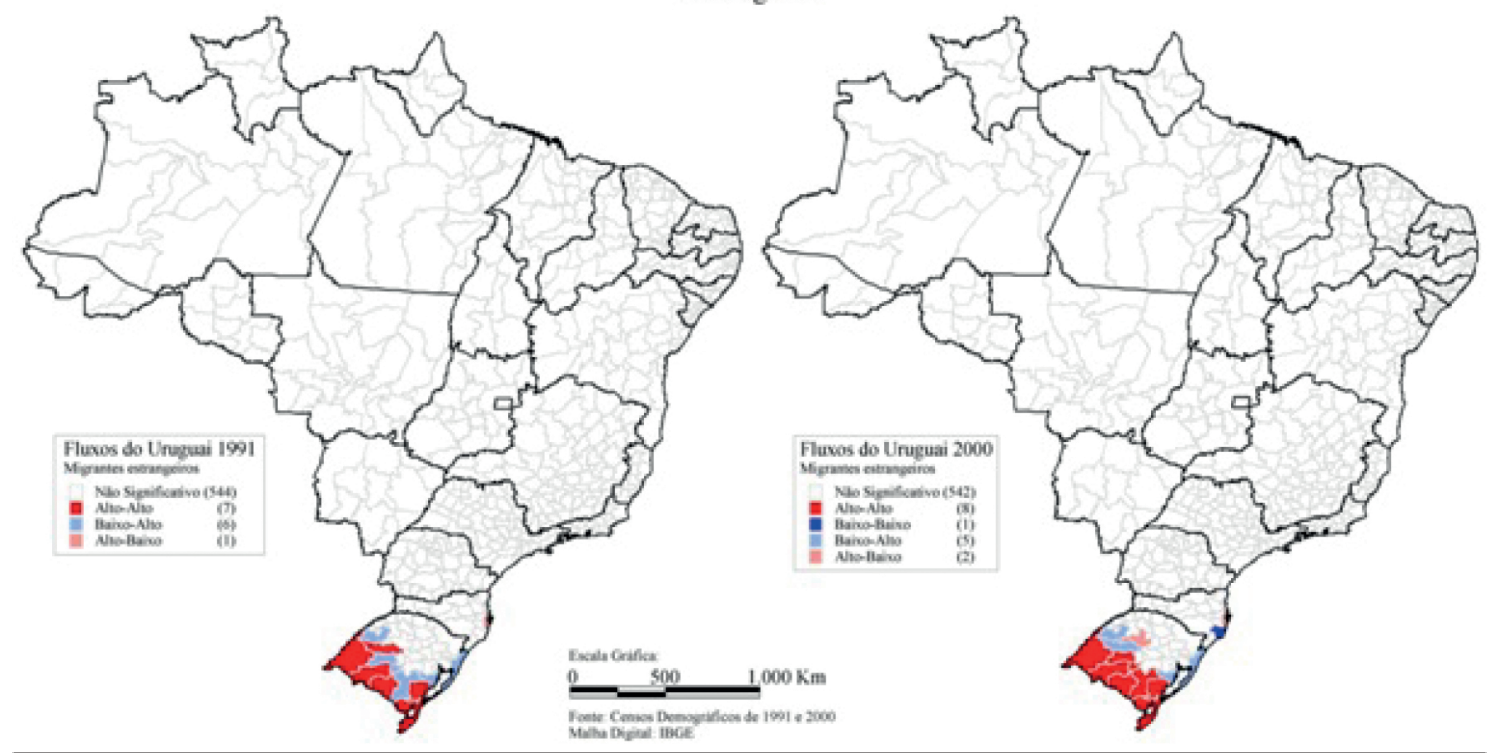

A análise dos padrões de associação espacial parece não deixar dúvida de que o aumento absoluto no número de migrantes oriundos desses quatro países, e, talvez, dos outros países da América do Sul, tem imprimido marcas no território brasileiro, recompondo as relações de fronteira e resignificando o cotidiano das comunidades de brasileiros e estrangeiros que convivem nesses espaços. Tendo em conta que as taxas calculadas fazem referência à proporção de migrantes internacionais no total de migrantes das microrregiões, cabe afirmar que as possibilidades de mobilidade populacional nessas microrregi- 
ões tem progressivamente incorporado a migração internacional como alternativa viável, aprofundando os laços econômicos, sociais e culturais com essas nações. É precisamente neste conjunto de circunstâncias que se espera reconhecer a formação de comunidades transfronteiriças, já que constituem espaços marcadamente influenciados por esses indivíduos em trânsito. Em todos os casos foi possível reconhecer um processo de difusão dos clusters de tipo alto-alto nas microrregiões limítrofes aos países, sugerindo um recorte territorial que delimitaria os contornos da fronteira brasileira com esses vizinhos.

Os limites territoriais entre os Estados Nacionais modernos configuram, no auge das técnicas cartográficas, a precisa delimitação do espaço de soberania de cada nação. O limite fornece, assim, a área total do que tradicionalmente se denomina de território. A fronteira, por sua vez, é fluída, não busca definir uma separação, mas sim aquilo que está sobreposto. Enquanto os limites separam, a fronteira integra. No interior da fronteira, contudo, pode-se ter também a formação de territórios, ou territorialidades, recorrendo a uma definição mais flexível do termo (Machado, 1998; Hissa, 2002; Haesbaert, 2004).

Desta maneira, enquanto a fronteira anuncia o fim do território tradicional, dialeticamente, ela também dinamiza e amplia o território flexível. O desafio que se coloca aqui, então, é o de se criar formas de reconhecer e acompanhar a fluidez das fronteiras e das territorialidades - supondo que a configuração das redes sociais de migração contribui para a "porosidade" das fronteiras segundo uma funcionalidade topológica. Assim, apresenta-se, na Figura 5, a sobreposição dos clusters de padrão alto-alto identificados em 2000, onde a mancha em vermelho que se estende desde o Acre até o Rio Grande do Sul configura uma aproximação das dimensões da fronteira brasileira com os países aqui analisados assumindo-se que a delimitação dos centros com alta correlação espacial é uma proxi das interações sócio-espaciais duradouras estabelecidas na fronteira. 
Figura 5: Dimensões da "fronteira" brasileira. Sobreposição dos clusters tipo alto-alto em 2000

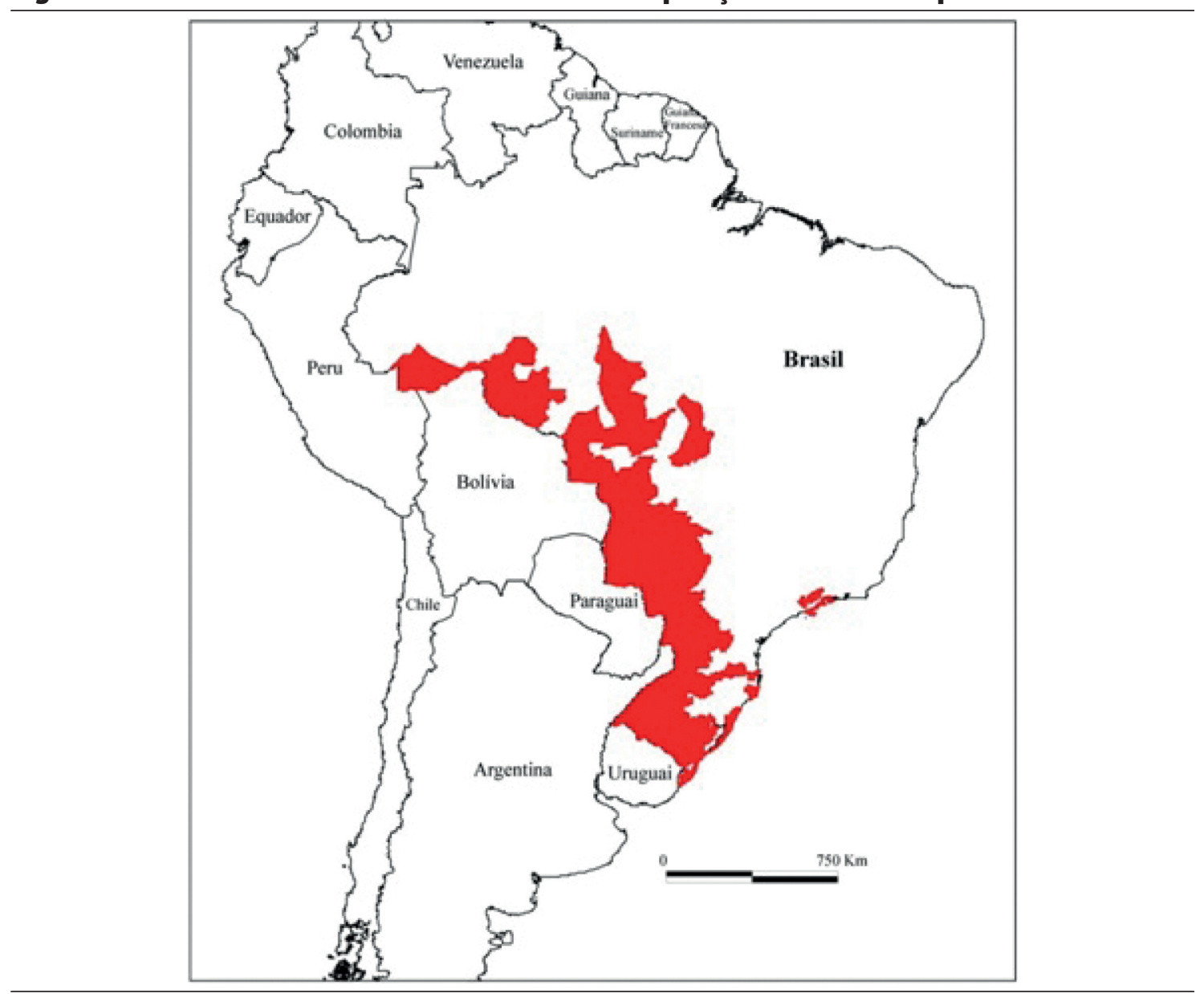

\section{CONSIDERAÇÕES FINAIS}

O esforço metodológico de reconhecer os clusters de aglomeração espacial dos migrantes forneceu importantes indicações do alcance das áreas de fronteira na composição das territorialidades das comunidades transfronteiriças. Em função disto, ressalta-se a importância da utilização dos métodos de autocorrelação espacial. Mais do que simplesmente reconhecer os espaços onde há altos valores absolutos ou relativos de migrantes desses países, os modelos de associação espacial como o Moran Global e os LISA permitem contrapor os indicadores de cada localidade a uma estrutura espacial de distribuição dos fenômenos. A existência das comunidades transfronteiriças, é obvio, não se explica através da distribuição espacial (resultados do modelo), antes, são as redes de relações sociais que, quando se mobilizam no espaço, reestruturam e ressignificam os lugares, podendo aproveitar ou se restringir com as características geográficas (relevo, clima, solo, etc.). Neste sentido, é importante ressaltar que o elemento central na identificação dessas territoriali- 
dades não é a delimitação do receptáculo, mas o reconhecimento do campo de ação espacial de um determinado grupo social.

Os resultados apresentados nos mapas deixam evidente que as trocas populacionais com Argentina, Bolívia, Paraguai e Uruguai vêm construindo uma fronteira em expansão, com trajetórias distintas de brasileiros e estrangeiros. Em cada fluxo, percebe-se um tipo diferenciado de relações com o Brasil, e a análise do perfil dos imigrantes permite especular que, não obstante haja uma tendência convergente de ampliação dos clusters nas áreas de fronteira, cada relação migratória deve estabelecer um padrão particular.

Nas últimas décadas a rede migratória brasileira vem apresentando um padrão de difusão/diversificação das conexões origem-destino, simultaneamente a uma sobreposição das migrações internas e internacionais nas áreas de fronteira, reforçando as comunidades locais e identidades transfronteiriças. Consequentemente, ocorre uma fragmentação dos espaços, estabelecendo hierarquias nas quais certos territórios exercem maior poder de atração e são mais eficientes em difundir o comportamento migratório. Determinadas mobilidades não utilizadas no passado passam a ficar cada vez mais presentes, não apenas em função do avanço das tecnologias de transporte e comunicação, mas também devido à própria configuração das redes migratórias no espaço. Neste sentido, observa-se uma complexificação do território junto com a ampliação e especialização dos tipos de mobilidades. Esses tipos se complementam, hierarquicamente e funcionalmente - alguns espaços terão a presença mais forte de uma mobilidade temporária/circular, outros irão funcionar apenas como pontos de passagem, e outros, ainda, serão destinos mais estáveis.

\section{REFERÊNCIAS}

1. ANSELIN, L. An introduction to EDA with GeoDa. Spatial Analysis Laboratory (SAL). Urbana-Champaign: Department of Agricultural and Consumer Economics; University of Illinois, 2003. Disponivel em: http://geodacenter.asu.edu/system/files/quicktour.pdf. Acessoem: 19 nov. 2010.

2. ANSELIN, L. Exploringspatial data withGeoDaTM: a workbook. Santa Barbara CA: Center forSpatiallyIntegrated Social Science, 2005. Disponívelem: https://www.geoda.uiuc.edu/documentation/tutorials. Acessoem: 15 nov. 2010.

3. ANSELIN, L.; SYABI, I.; KHO, Y. GeoDa: an introduction to spatial data analysis. Geographical Analysis, Columbus, v. 38, n. 1, p. 5-22, Jan. 2006.

4. ANSELIN, Luc. Local Indicators of Spatial Association-LISA. Geographical Analysis, Columbus, v.27, n. 2, p. 93-115, Apr. 1995. 
5. BIVAND, R. S.; PEBESMA, E. J.; GÓMEZ-RUBIO, V. Applied spatial data analysis with r. New York: Springer, 2008.

6. BRAGA, Fernando; FAZITO, Dimitri. Análise de redes sociais e as conexões territoriais da migração no Brasil: padrões estruturais da migração interna entre 1980 e 2000. In: ENCONTRO NACIONAL DE ESTUDOS POPULACIONAIS, 18., Caxambu. Anais... Caxambu: ABEP, 2010.

7. BRECHER, Jeremy; COSTELLO, Tim; SMITH, Brendan. Globalization From Below. Cambridge: South End Press, 2000.

8. CÂMARA, G.; CARVALHO, M.; CRUZ, O. G.; CORREA, V. Análise espacial de áreas. In: FUCKS, Suzana. et al.Análise espacial de dados geográficos. São José dos Campos: INPE, 2003. Cap.5. Disponível em: <http://www.dpi.inpe.br/gilberto/livro/analise/>. Acesso em: 15 nov. 2010.

9. CARVALHO, J. A. M.; GARCIA, R. A. Estimativas decenais e qüinqüenais de saldos migratórios e taxas líquidas de migração do Brasil, por situação do domicílio, sexo e idade, segundo Unidade da Federação e macrorregião, entre 1960 e 1990, e estimativas de emigrantes internacionais do Período 1985/1990. Belo Horizonte: CEDEPLAR, 2002. Relatório de Pesquisa.

10. CARVALHO, J. A. M.; MACHADO, C.C. Quesitos sobre migração no Censo Demográfico de 1991. Revista Brasileira de Estudos Populacionais, Campinas, v. 9, n. 1, p. 22-34, jan./jul. 1992.

11. CASTLES, S.; MILLER, M. The age of migration. New York: The Guilford Press, 2003.

12. DE HAAN, A. Towards a new poverty agenda: social policies and economic transformation. Sage: New Delhi, 2010.

13. FAIST, T. Dual Citizenship as overlapping membership. Malmö: School of International Migration and Ethnic Relations, 2001. (Willy Brandt Series of Working Papers 3/01)

14. FONER, N. 'What's new about transnationalism? New York immigrants today and at the turn of the century,' Diaspora, New York, v. 6, n. 3, p. 355-75, Jan./Jun. 1997.

15. FREITAS, Patrícia Tavares de. Imigração e trabalho: determinantes históricas da formação de um circuito de subcontratação de imigrantes bolivianos para o trabalhoem oficinas de costura na cidade de São Paulo. In: ENCONTRO NACIONAL DE ESTUDOS POPULACIONAIS. 17., Caxambu. Anais...Caxambu:ABEP, 2010.

16. GARCIA, Ricardo Alexandrino; SOARES, Weber. Migração internacional de retorno ao Brasil: efeitos diretos e indiretos. In: SEMINÁRIO SOBRE A ECONOMIA MINEIRA, 12., 2006. Diamantina, Anais... Belo Horizonte: UFMG;CEDEPLAR, 2006.

17. GLICK SCHILLER, N.; BASCH, L.; SZANTON, C. B. Towards a transnational perspective on migration:race, class, ethnicity and nationalism reconsidered. New York: New York Academy of Sciences, 1992.

18. GUARNIZO, Luis Eduardo. Migración, globalización y sociedad: teorías y tendencias en el siglo XX. In: ARDILA, Gerardo (Org.). Colombia: migraciones, transnacionalismo y desplazamiento. Bogotá: Cátedra Manuel Ancízar; Universidad Nacional de Colombia, 2006. (Colección CEES) 
19. GUARNIZO, Luis Eduardo; PORTES, Alejandro; HALLER, William. Assimilation and transnationalism: determinants of transnationalpoliticalactionamongcontemporarymigrants. American Journal of Sociology, Chicago, v. 108, n. 6, p. 1211-48, May. 2003.

20. GUILMOTO, C. Z.; SANDRON, F. The internal dynamics of migration networks in developing countries. Population: an English Selection, Paris, v.13, n. 2, p. 135-164, Jul./Dec. 2001.

21. HAESBAERT, Rogério. O mito da desterritorialização: do fim dos territórios a multiterritorilidade. Rio de Janeiro: Bertrand Brasil, 2004.

22. HANNERZ, Ulf. Transnational connections. London: Routledge, 1996.

23. HISSA, Cassio E. V. A mobilidade das fronteiras: inserções da geografia na crise da modernidade. Belo Horizonte: Editora UFMG, 2002.

24. INSTITUTO BRASILEIRO DE GEOGRAFIA E ESTATÍSTICA -IBGE. Divisão do Brasil em mesorregiões e microrregiões geográficas. Rio de Janeiro: IBGE, 1990. 20p. (Relatório Técnico)

25. JAKOB, Alberto A. E. A migração transfronteiriça na Amazônia Legal Brasileira. In: CONGRESSO DA ASSOCIAÇÃO LATINO AMERICANA DE POPULAÇÃO. 4., 2010. Havana. Anais.....Havana: ALAP: 2010.

26. JORDAN, Bill; DÜVELL, Franck. Migration, the boundaries of equality and justice. Cambridge: Polity Press, 2003. p.1-26.

27. KRITZ, M. M.; ZLOTNIK, Hania. Global interactions: migration systems, processes, and policies. In: KRITZ, M. M.; LIM, L. L.; ZLOTNIK, H. International migration systems: a global approach.Oxford: Claredon Press, 1992. p.1-16.

28. LIMA, E. E. C.; BRAGA, Fernando. Da rotatividade migratória a baixa migração: uma análise dos novos padrões da mobilidade populacional no Brasil. In: ENCONTRO NACIONAL DE ESTUDOS POPULACIONAIS. 17., Caxambu. Anais...Caxambu:ABEP, 2010.

29. LOBO, Carlos; STEFANI, João; SOUSA, Guilherme. Migração na América do Sul: territorialidades e espacialidades da imigração sulamericana no Brasil. In: ENCONTRO NACIONAL SOBRE MIGRAÇÕES, 4., Rio de Janeiro. Anais... Rio de Janeiro: ABEP, 2005.

30. MACHADO, Lia O. Limites, fronteiras e redes. In: STROHAECKER, T.M. et al. Fronteiras e espaço global. Porto Alegre: AGB, 1998. p.41-49.

31. MARQUES, Denise Helena França. Circularidade na fronteira do Paraguai e Brasil:o estudo de caso dos “brasiguaios". 2009. 171f. Tese (Doutorado).- Centro de Desenvolvimento e Planejamento Regional, Universidade Federal de Minas Gerais, Belo Horizonte, 2009.

32. MASSEY, D.S. et al. Theories of international migration: a review and appraisal. Population and Development Review, New York, v. 19, n. 3, p. 431-466, Sep. 1993.

33. MELLO ALMEIDA, Leonel I. Argentina e Brasil:a balança de poder no Cone Sul. São Paulo: Annablume, 1996.

34. NÓBREGA, Ricardo. Migração e globalização popular: trabalhadores bolivianos na pequena indústria têxtil de São Paulo In: ENCONTRO NACIONAL SOBRE MIGRAÇÕES, 6., 2009. Belo Horizonte. Anais... Belo Horizonte: ABEP, 2009. 
35. NOVICK, Susana (Org.)Las migraciones en América Latina.Buenos Aires: Catálogos, 2008.

36. PACHECO, Carlos Américo; PATARRA, Neide. Movimentos migratórios nos anos 80: Novos Padrões? In: ENCONTRO NACIONAL SOBRE MIGRAÇÕES, 1., 1997. Curitiba. Anais... Curitiba: ABEP, 1997.

37. PALAU, T. Migrações Transfronteiriças entre Brasil e Paraguai: o caso dos brasiguaios. In: PATARRA, N.L. (coord.). Migrações Internacionais: Herança Internacionais no Brasil Contemporâneo. Campinas: FNUAP. Vol.1. 1995.

38. PARDO, María Fabiola. La inmigración y el devenir de las sociedades multiculturales: perspectivas políticas y teóricas. In: NOVICK, Susana (Org.) Las migraciones en América Latina. Buenos Aires: Catálogos, 2008. p.153-171.

39. PATARRA, N. L.; BAENINGER, R. Mobilidade espacial da população no Mercosul: metrópoles e fronteiras. Revista Brasileira de Ciências Sociais, São Paulo, v.21, n. 60, p. 83-181, fev. 2006.

40. PATARRA, Neide Lopes; BAENINGER, Rosana. Migrações internacionais, globalização e blocos de integração econômica- Brasil no Mercosul. In: ENCONTRO NACIONAL DE ESTUDOS POPULACIONAIS. 14., 2004, CAXAMBU, MG; CONGRESO DE LA ASOCIACIÓN LATINO-AMERICANA DE POBLACÓN - ALAP, 1., 2002. Caxambu. Pobreza, desigualdade e exclusão social, Anais... Campinas: ABEP, 2004.

41. PELLEGRINO, Adela. Drenaje, movilidad, circulación: nuevas modalidades de lamigracióncalificada. In: SIMPOSIO SOBRE MIGRACIÓN INTERNACIONAL EN LAS AMÉRICAS. 1., 2000. San Jose. Anais...San José: CEPAL/CELADE/OIM 2000.

42. PELLEGRINO, Adela. Éxodo, movilidad y circulación: nuevas modalidades de lamigracióncalificada. Notas de Población, Santiago de Chile, v. 28, n. 73, p. 129-162, sep. 2001.

43. PORTES, Alejandro. Globalization from below: the rise of transnational communities. Princeton: Princeton University Press, 1997.

44. PRIES, L. (Org.). Migration and Transnational Social Spaces. Aldershot: Ashgate, 1999.

45. SALA, Gabriela Adriana. Características demográficas e sócio-ocupacionais dos migrantes nascidos nos países do Cone Sul residentes no Brasil. 2005. 261 f. Tese (Doutorado).- Centro de Desenvolvimento e Planejamento Regional, Universidade Federal de Minas Gerais, Belo Horizonte, 2005.

46. SALES, Teresa. Migrações de fronteira entre o Brasil e os países do Mercosul. Revista Brasileira de Estudos de População, Campinas, v. 13, n. 1, p. 87-98, jan./jul.. 1996.

47. SALIM, A. C. A questão dos brasiguaios e o Mercosul. In: PATARRA, Neide Lopes. Emigração e imigração internacionais no Brasil contemporâneo. Campinas: FNUAP, 1995. p.144-159.

48. SAYAD, A. A imigração ou os paradoxos da alteridade. São Paulo: EDUSP, 1998. 299 p.

49. SKELDON, Ronald. International migration as a tool in development policy. Population and Development Review, New York, v. 34, n. 1, p. 1-18, Mar. 2008.

50. SMITH, M.P.; GUARNIZO, L.E. (Orgs.). Transnationalism from Below. New Brunswick, NJ: Transaction Publishers, 1998. 
51. SOUCHAUD, Sylvain; CARMO, Roberto Luiz do; FUSCO, Wilson. Mobilidade Populacional e Migração no Mercosul: A fronteira do Brasil com Bolívia e Paraguai. Teoria \& Pesquisa, São Carlços, SP, v. 16, n. 01, p. 39-60, jan./jun. 2007.

52. SPRANDEL, Marcia Anita. Brasileiros na fronteira com o Paraguai.EstudosAvançados, São Paulo, v. 20, n. 57, p. 137-156. 2006.

53. VERTOVEC, Steven. Transnational challenges to the 'new' multiculturalism. Oxford: ESRC Transnational Communities Programme, 2001. (WorkingPaper, WPTC-01-06). Disponível em: <www.transcomm.ox.ac.uk>. Acesso em: 18 jun. 2011.

54. YÚDICE, George. A conveniência da cultura:usos da cultura na era global. Belo Horizonte: Editora UFMG, 2006. 615 p.

55. ZHANG, Tonglin; LIN, Ge. Identification of local clusters for count data: a model-based moran'si test, 2007. p 1-27. 